\title{
IPNA clinical practice recommendations for the diagnosis and management of children with steroid-resistant nephrotic syndrome
}

\author{
Agnes Trautmann ${ }^{1} \cdot$ Marina Vivarelli $^{2} \cdot$ Susan Samuel ${ }^{3} \cdot$ Debbie Gipson $^{4} \cdot$ Aditi Sinha $^{5} \cdot$ Franz Schaefer $^{1} \cdot \mathrm{Ng} \mathrm{Kar} \mathrm{Hui}^{6}$. \\ Olivia Boyer ${ }^{7,8} \cdot$ Moin A Saleem $^{9} \cdot$ Luciana Feltran $^{10}$ - Janina Müller-Deile ${ }^{11}$ • Jan Ulrich Becker ${ }^{12}$. Francisco Cano ${ }^{13}$. \\ Hong Xu ${ }^{14}$. Yam Ngo Lim ${ }^{15}$. William Smoyer ${ }^{16}$. Ifeoma Anochie ${ }^{17} \cdot$ Koichi Nakanishi $^{18}$. Elisabeth Hodson ${ }^{19}$. \\ Dieter Haffner $20,21,22$ on behalf of the International Pediatric Nephrology Association
}

Received: 21 December 2019 / Revised: 7 February 2020 / Accepted: 21 February 2020 / Published online: 7 May 2020

(C) The Author(s) 2020

\begin{abstract}
Idiopathic nephrotic syndrome newly affects 1-3 per 100,000 children per year. Approximately $85 \%$ of cases show complete remission of proteinuria following glucocorticoid treatment. Patients who do not achieve complete remission within 4-6 weeks of glucocorticoid treatment have steroid-resistant nephrotic syndrome (SRNS). In 10-30\% of steroid-resistant patients, mutations in podocyte-associated genes can be detected, whereas an undefined circulating factor of immune origin is assumed in the remaining ones. Diagnosis and management of SRNS is a great challenge due to its heterogeneous etiology, frequent lack of remission by further immunosuppressive treatment, and severe complications including the development of end-stage kidney disease and recurrence after renal transplantation. A team of experts including pediatric nephrologists and renal geneticists from the International Pediatric Nephrology Association (IPNA), a renal pathologist, and an adult nephrologist have now developed comprehensive clinical practice recommendations on the diagnosis and management of SRNS in children. The team performed a systematic literature review on 9 clinically relevant PICO (Patient or Population covered, Intervention, Comparator, $\underline{\text { Outcome) }}$ questions, formulated recommendations and formally graded them at a consensus meeting, with input from patient representatives and a dietician acting as external advisors and a voting panel of pediatric nephrologists. Research recommendations are also given.
\end{abstract}

Keywords Steroid-resistant nephrotic syndrome $\cdot$ Children $\cdot$ Chronic kidney disease $\cdot$ Genetics $\cdot$ Outcome $\cdot$ Pediatrics Immunosuppressive treatment

\section{Introduction}

Idiopathic nephrotic syndrome (NS), characterized by severe proteinuria, hypoalbuminemia, and/or presence of edema [1, 2], newly affects about $1-3$ per 100,000 children aged below 16 years [3-5]. Approximately $85 \%$ of cases experience complete remission of proteinuria following daily oral prednisolone/prednisone (PDN) treatment at standard doses

Electronic supplementary material The online version of this article (https://doi.org/10.1007/s00467-020-04519-1) contains supplementary material, which is available to authorized users.

Dieter Haffner

Haffner.Dieter@mh-hannover.de

Extended author information available on the last page of the article
[6]. Those who do not achieve remission after 4-6 weeks of treatment are presumed to have steroid resistant NS (SRNS) [7]. The duration of PDN required before a patient is considered steroid-resistant is a matter of discussion and longer treatment periods (6-8 weeks), as well as additional intravenous methylprednisolone (MPDN) pulses, have been reported [6].

In 10-30\% of patients with non-familial SRNS, mutations in podocyte-associated genes can be detected, whereas an undefined circulating factor(s) is assumed in the remaining cases [8-10]. The principal histopathological entities encountered in SRNS are focal and segmental glomerulosclerosis (FSGS), minimal change disease (MCD), and diffuse mesangial sclerosis. Treatment usually includes inhibitors of the reninangiotensin-aldosterone system (RAASi) and calcineurin inhibitors (CNI) in patients with non-genetic forms of SRNS. With this approach, complete or partial remission can be achieved in $50-70 \%$ of cases $[6,7]$. 
Management of SRNS is a great challenge due to its heterogeneous etiology, frequent lack of remission induced by immunosuppressive treatment, and complications including drug toxicity, infections, thrombosis, the development of end-stage kidney disease (ESKD), and recurrence after renal transplantation [11]. There are currently no evidence-based, systematically developed recommendations on the diagnosis and management of children with SRNS available, with the exception of a focused document from KDIGO (Kidney Disease: Improving Global Outcomes) Glomerulonephritis guideline [6]. Therefore, the International Pediatric Nephrology Association (IPNA) convened a clinical practice recommendation (CPR) workgroup in December 2018 to develop CPRs for the diagnosis and management of children with SRNS. Future research recommendations regarding key outcome measures in patients with SRNS are also presented.

\section{Methods}

\section{Overview of the guideline project}

We have followed the RIGHT (Reporting Items for practice Guidelines in HealThcare) Statement for Practice Guidelines [12]. Three groups were assembled: a core leadership group, an external expert group, and a voting panel. The core group comprised 18 members of IPNA, including pediatric nephrologists, renal geneticists, epidemiologists, an adult nephrologist, and a renal pathologist. The individual expertise and responsibilities of the core group members are given in Supplementary Table S1. The external expert group included 3 patient representatives and one dietician. The patient representatives discussed the manuscript provided by the core group members within their local parents' association, and their suggestions were then incorporated into the manuscript. The voting panel included 23 pediatric nephrologists including 3-5 representatives of each IPNA Regional Society with expertise in the management of SRNS in children. Voting group members were asked by electronic questionnaire to provide a level of agreement on a 5-point scale (strongly disagree, disagree, neither agree/disagree, agree, strongly agree) (Delphi method). For topics that failed to achieve a $70 \%$ level of consensus, the recommendations were re-evaluated and modified by the core group and then reviewed again by the voting panel until a consensus level of $>70 \%$ was achieved.

\section{Developing the PICO questions}

We developed PICO (Patient or Population covered, Intervention, Comparator, Outcome) questions as follows [13]: Population: Children ( $>3$ months and $<18$ years) with SRNS; Intervention and Comparators: treatment compared with no treatment, other treatment or placebo; Outcomes
Addressed: We addressed recommendations for the diagnosis, treatment, and follow-up of children with SRNS (including efficacy to induce remission and side effects of medications).

\section{Literature search}

The PubMed database was searched for studies published by 15 September 2019; all systematic reviews of randomized controlled trials (RCTs) on treatment of SRNS in children, RCTs, prospective uncontrolled trials, observational studies, and registry studies on diagnosis and treatment of children with SRNS, restricted to human studies in English. Where possible, metaanalyses of RCTs using risk ratios were cited from the updated Cochrane systematic review regarding interventions for childhood steroid resistant NS (SRNS) [14]. Further details and a summary of the publications used for this CPR are given in the Supplementary material (Supplementary Tables S2-S5).

\section{Grading system}

We followed the grading system of the American Academy of Pediatrics (Fig. 1; [16]). The quality of evidence was graded as High (A), Moderate (B), Low (C), Very low (D), or Not applicable (X). The latter refers to exceptional situations where validating studies cannot be performed because benefit or harm clearly predominates. This letter was used to grade contra-indications of therapeutic measures and safety parameters. The strength of a recommendation was graded as strong, moderate, weak, or discretionary (when no recommendation can be made).

\section{Limitations of the guideline process}

SRNS is a rare disease. Consequently, the sizes and numbers of some RCTs were small and of poor methodological quality so most recommendations are weak to moderate. Due to the limited budget of this IPNA initiative, patient representatives and dieticians were only included as external experts.

\section{Clinical practice recommendations}

\section{Definitions and diagnostic work-up}

\section{Definitions}

- We recommend quantification of proteinuria by protein/ creatinine ratio (UPCR) in either a first morning (AM) urine or 24-h urine sample at least once before defining a patient as SRNS and/or starting alternative immunosuppression. We suggest using this baseline value for assessment of subsequent response (grade A, strong recommendation). 
Fig. 1 Matrix for grading of evidence and assigning strength of recommendations as currently used by the American Academy of Pediatrics. Reproduced with permission from [15]

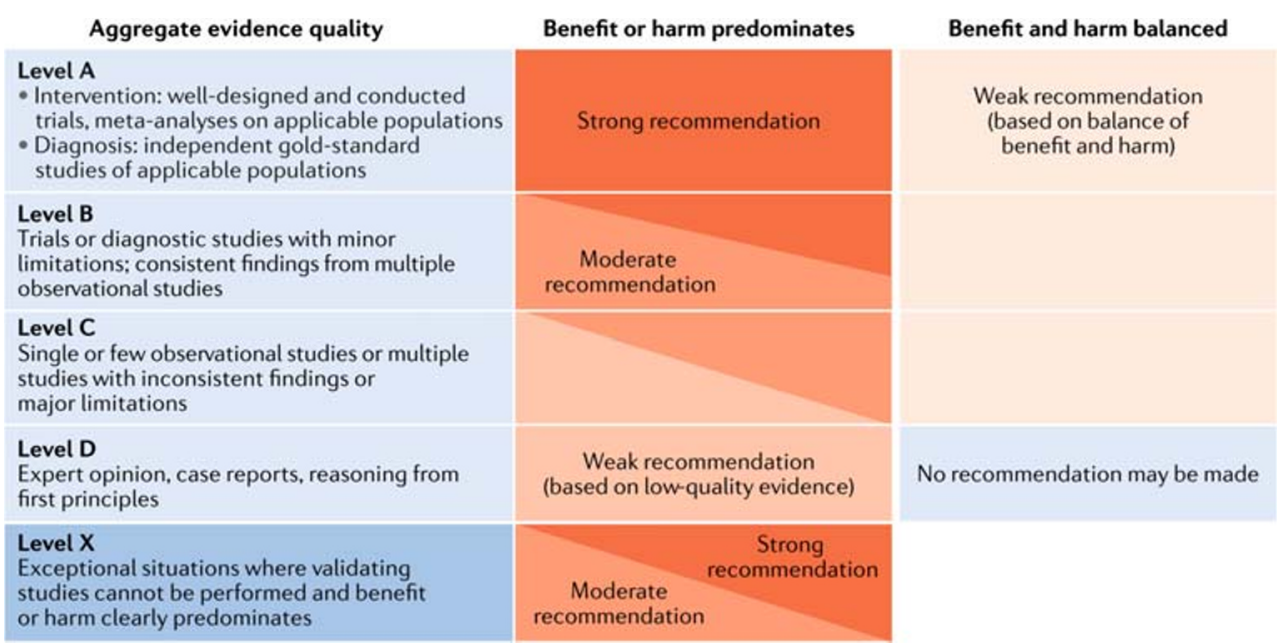

\section{Definition of SRNS}

- We suggest using the definitions listed in Table 1 for the diagnosis and management of SRNS (grade B, moderate recommendation).

- We suggest using the "confirmation period," which is the time period between 4 and 6 weeks from start of oral PDN at standard doses, to assess the response to further treatment with glucocorticoids and initiate RAASi (grade C, weak recommendation). We also recommend performing genetic testing and/or a renal biopsy at this time (grade B, moderate recommendation).

- We suggest the submission of histological, clinical, and genetic data from all SRNS patients into patient registries and genetic databases to help improve our understanding of the disease and its treatment (ungraded).

\section{Evidence and rationale}

\section{Assessment of proteinuria}

The conventional definition of NS in children is proteinuria $>$ $40 \mathrm{mg} / \mathrm{h} / \mathrm{m}^{2}$ or $\geq 1000 \mathrm{mg} / \mathrm{m}^{2} /$ day or urinary protein creatinine ratio (UPCR) $\geq 200 \mathrm{mg} / \mathrm{mmol}(2 \mathrm{mg} / \mathrm{mg}$ ) or $3+$ on urine dipstick plus either hypoalbuminemia $(<30 \mathrm{~g} / \mathrm{l})$ or edema [17]. Urinary dipstick analysis is useful for screening and at home monitoring of proteinuria, but therapeutic decisions should be based on at least one precise quantification of proteinuria, i.e., UPCR on a first-morning urine sample, or 24-h urine collection after treatment for $\geq 4$ weeks with full-dose PDN. Firstmorning urine samples are preferred over random spot samples to reduce the influence of orthostatic proteinuria $[18,19]$. Given the linear relationship between UPCR in spot and 24-h urine protein, determination of UPCR is recommended. If either UPCR measurement is $\geq 200 \mathrm{mg} / \mathrm{mmol}(2 \mathrm{mg} / \mathrm{mg})$, then treatment for SRNS should begin. Semiquantitative expression of dipstick results is given in Supplementary Table S6.
The initial treatment of children with idiopathic NS usually comprises oral PDN $60 \mathrm{mg} / \mathrm{m}^{2} /$ day or $2 \mathrm{mg} / \mathrm{kg} /$ day (maximum $60 \mathrm{mg}$ /day) for 4-6 weeks, followed by $40 \mathrm{mg} / \mathrm{m}^{2}$ or $1.5 \mathrm{mg} / \mathrm{kg}$ per dose on alternate days (QOD) for another 46 weeks. After the initial 4 weeks of full-dose oral PDN, a child can achieve complete remission (UPCR $\leq 20 \mathrm{mg} / \mathrm{mmol}$ $(0.2 \mathrm{mg} / \mathrm{mg})$ or negative or trace dipstick on three or more consecutive occasions), which confirms SSNS. If partial remission is observed, given the fact that a small percentage of children achieve complete remission if given 2 additional weeks of time, the "confirmation period" begins. During this time, responses to further daily oral PDN with or without 3 pulses of MPDN $\left(500 \mathrm{mg} / \mathrm{m}^{2}\right.$ or $15 \mathrm{mg} / \mathrm{kg}$ ), and RAASi are ascertained (Fig. 2). If complete remission is achieved by 6 weeks, the child is defined as "late responder" SSNS and treated as SSNS. If no remission is achieved by 6 weeks, the diagnosis of SRNS is confirmed (Fig. 2). We recommend performing a renal biopsy as well as obtaining genetic testing results (where available) as soon as possible, ideally within the 2 -week confirmation period. If genetic results are not available at the end of the confirmation period, we suggest to start treatment with $\mathrm{CNI}$ and to reassess treatment after receiving genetic results. In the setting of low-resource countries where genetic and/or histopathology assessment is not available, immediate immunosuppressive treatment with CNI may be started. If CNI are not available intravenous or oral cyclophosphamide (CPH) may be started (vide infra). Details on evidence and rationale for these definitions are given in the Supplementary Material.

\section{Definition of CNI-resistant nephrotic syndrome} cause, a substantial proportion will respond to CNIs in a variable amount of time (weeks to months). Children with initial
Among those children defined as SRNS without a genetic 
Table 1 Definitions relating to nephrotic syndrome in children

\begin{tabular}{|c|c|}
\hline Term & Definition \\
\hline Nephrotic-range proteinuria & $\begin{array}{l}\text { UPCR } \geq 200 \mathrm{mg} / \mathrm{mmol}(2 \mathrm{mg} / \mathrm{mg}) \text { in first morning void or } 24 \mathrm{~h} \text { urine sample } \\
\geq 1000 \mathrm{mg} / \mathrm{m}^{2} / \text { day corresponding to } 3+\text { or } 4+\text { by urine dipstick }\end{array}$ \\
\hline Nephrotic syndrome & $\begin{array}{l}\text { Nephrotic-range proteinuria and either hypoalbuminemia (serum albumin }<30 \mathrm{~g} / \mathrm{l} \text { ) or } \\
\text { edema when serum albumin level is not available }\end{array}$ \\
\hline SSNS & $\begin{array}{l}\text { Complete remission within } 4 \text { weeks of prednisone or prednisolone (PDN) at standard dose } \\
\left(60 \mathrm{mg} / \mathrm{m}^{2} / \text { day or } 2 \mathrm{mg} / \mathrm{kg} / \text { day, maximum } 60 \mathrm{mg} / \text { day). }\right.\end{array}$ \\
\hline SRNS & Lack of complete remission within 4 weeks of treatment with PDN at standard dose \\
\hline Confirmation period & $\begin{array}{l}\text { Time period between } 4 \text { and } 6 \text { weeks from PDN initiation during which response to further } \\
\text { oral PDN and/or pulses of iv MPDN and RAASi are ascertained in patients achieving } \\
\text { only partial remission at } 4 \text { weeks. A patient achieving complete remission at } 6 \text { weeks is } \\
\text { defined as a late responder. A patient not achieving complete remission at } 6 \text { weeks } \\
\text { although he had achieved partial remission at } 4 \text { weeks is defined as SRNS. }\end{array}$ \\
\hline Complete remission & $\begin{array}{l}\text { UPCR (based on first morning void or } 24 \mathrm{~h} \text { urine sample) } \leq 20 \mathrm{mg} / \mathrm{mmol}(0.2 \mathrm{mg} / \mathrm{mg} \text { ) or } \\
\text { negative or trace dipstick on three or more consecutive occasions. }\end{array}$ \\
\hline Partial remission & $\begin{array}{l}\text { UPCR (based on first morning void or } 24 \mathrm{~h} \text { urine sample) }>20 \text { but }<200 \mathrm{mg} / \mathrm{mmol} \text { and, if } \\
\text { available, serum albumin } \geq 30 \mathrm{~g} / \mathrm{l} \text {. }\end{array}$ \\
\hline Relapse & $\begin{array}{l}\text { Recurrence of nephrotic-range proteinuria. In children, relapse is commonly assessed by } \\
\text { urine dipstick and is thus defined as dipstick } \geq 3+\text { on } 3 \text { consecutive days, or UPCR } \\
\geq 200 \mathrm{mg} / \mathrm{mmol}(2 \mathrm{mg} / \mathrm{mg}) \text { on a first morning urine sample, with or without reappearance } \\
\text { of edema in a child who had previously achieved partial or complete remission. }\end{array}$ \\
\hline CNI-resistant SRNS & $\begin{array}{l}\text { Absence of at least partial remission after } 6 \text { months of treatment with a CNI at adequate } \\
\text { doses and/or levels. }\end{array}$ \\
\hline Multi-drug-resistant SRNS & $\begin{array}{l}\text { Absence of complete remission after } 12 \text { months of treatment with } 2 \text { mechanistically distinct } \\
\text { steroid-sparing agents at standard doses (see text). }\end{array}$ \\
\hline Secondary steroid resistance & Children with initial steroid-sensitivity who in subsequent relapses develop SRNS \\
\hline $\begin{array}{l}\text { Recurrent nephrotic syndrome } \\
\text { post-renal transplantation }\end{array}$ & $\begin{array}{l}\text { A child with SRNS presenting post-renal transplantation with a relapse of nephrotic-range } \\
\text { proteinuria in the absence of other apparent causes and/or podocyte foot process } \\
\text { effacement on kidney biopsy. This diagnosis should also be considered in case of } \\
\text { persistent proteinuria (UPCR } \geq 100 \mathrm{mg} / \mathrm{mmol}(1 \mathrm{mg} / \mathrm{mg}) \text { in a previously anuric patient, } \\
\text { or an increase of UPCR } \geq 100 \mathrm{mg} / \mathrm{mmol}(1 \mathrm{mg} / \mathrm{mg}) \text { in a patient with prevalent proteinuria } \\
\text { at the time of transplant in the absence of other apparent causes. }\end{array}$ \\
\hline
\end{tabular}

$U P C R$ urine protein/creatinine ratio, SSNS steroid sensitive nephrotic syndrome, SRNS steroid-resistant nephrotic syndrome, $P D N$ prednisolone or prednisone, $M P D N$ methylprednisolone, RAASi renin-angiotensin-aldosterone system, $C N I$ calcineurin inhibitor

SRNS who are CNI responders subsequently either remain in stable remission with no or infrequent relapses or may develop secondary SSNS. Resistance to CNIs is defined when a child fails to attain at least partial remission after at least 6 months of CNI treatment administered at adequate doses and blood levels.

\section{Definition of multi-drug resistant nephrotic syndrome}

Children resistant to CNIs may be treated with other steroidsparing agents (see "Developing the PICO questions"; Fig. 2 and Supplementary Table S2). Patients with SRNS are defined as "multi-drug resistant" in the absence of complete remission after 12 months of treatment with 2 mechanistically distinct steroid-sparing agents (including CNIs) administered at standard doses.

\section{Initial diagnostic workup of a child with SRNS}

- We recommend obtaining a careful family history for renal and extra-renal manifestations including asking about consanguinity. Where renal diseases are present in family members, the age at onset, clinical course including response to medications, renal function, and renal biopsy and genetic testing results should be obtained wherever possible (grade A, strong recommendation).

- We recommend careful physical examination of the patient including a meticulous search for extra-renal manifestations such as skeletal, neurological, eye, ear and urogenital abnormalities, and for secondary causes (mainly infectious) of NS (Table 2) (grade A, strong recommendation).

- We suggest that the blood, serum, and urine tests listed in Table 2 be performed to search for immunological or infectious causes of SRNS and to evaluate the degree of 


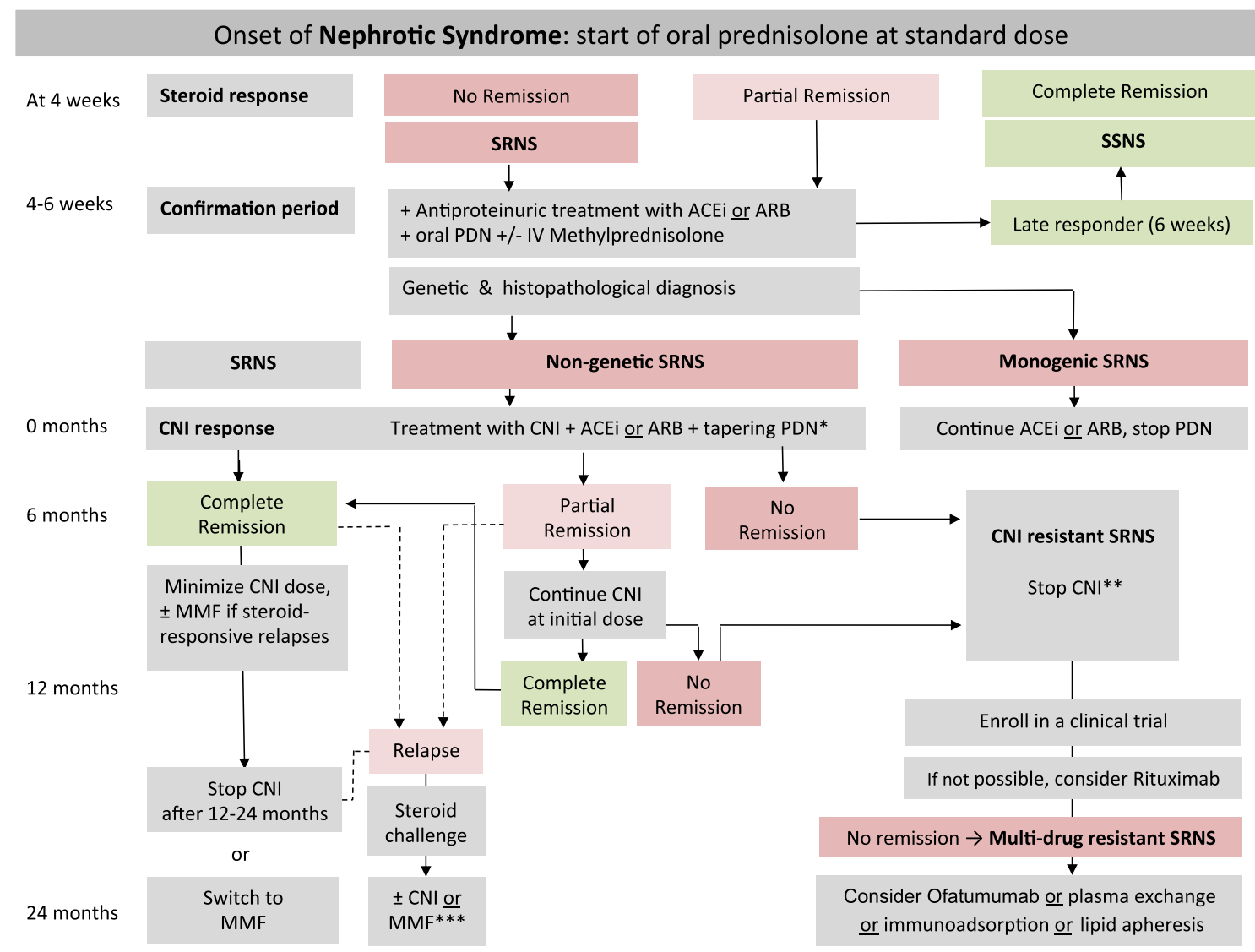

Fig. 2 Algorithm for the management of children with nephrotic syndrome. Patients are characterized according to response to a 4-week treatment with oral prednisolone (PDN). Patients showing no complete remission enter the confirmation period in which responses to further oral prednisolone (PDN) with or without methylprednisolone (MPDN) pulses in conjunction with either angiotensin-converting enzyme inhibitors (ACEi) or angiotensin-receptor blockers (ARBs) are ascertained and genetic and histopathological evaluation is initiated. Patients with nongenetic SRNS should be candidates for further immunosuppression, whereas those with monogenetic forms are not (further details are given in the text). In the setting of low resource countries where genetic and/or histopathology assessment is not available, immediate

immunosuppressive treatment with CNI may be started. If CNI are not available intravenous or oral cyclophosphamide may be started. * =We suggest tapering PDN after CNI initiation as follows: $40 \mathrm{mg} / \mathrm{m}^{2}$ QOD for 4 weeks, $30 \mathrm{mg} / \mathrm{m}^{2}$ QOD for 4 weeks, $20 \mathrm{mg} / \mathrm{m}^{2}$ QOD for 4 weeks, $10 \mathrm{mg} / \mathrm{m}^{2}$ QOD for 8 weeks, and discontinuing thereafter; $* *=\mathrm{CNI}$ may be continued in case of partial remission; $* * *=$ in cases of no complete response within 4 weeks, frequent relapses or side effects of medications, we recommend following the refractory SRNS protocol; SRNS, steroid-resistant nephrotic syndrome; ACEi, angiotensinconverting enzyme inhibitor; ARB, angiotensin-receptor blocker; PDN, prednisolone; IV, intravenous; CNI, calcineurin inhibitor; MMF, mycophenolate mofetil

proteinuria, estimated GFR, and renal histology (grade B, moderate recommendation).

- We suggest offering urinalysis to siblings of SRNS patients even before genetic testing is done (grade $\mathrm{C}$, moderate recommendation).

\section{Evidence and rationale}

Early identification of genetic forms of SRNS (listed in Table 3) is important, as these patients are unlikely to benefit from prolonged and potentially harmful immunosuppression. Delineation of family history to recognize

familial forms and a careful physical examination to identify extra-renal features (given in Supplementary Table S7) of genetic conditions are essential. Occasionally, SRNS can be secondary to infectious causes, mainly cytomegalovirus (CMV), human immunodeficiency virus (HIV), hepatitis B, malaria, parvovirus B19, and syphilis. Other causes of SRNS can be sickle-cell disease, lymphoma, membranous nephropathy, membranoproliferative glomerulonephritis, C3 glomerulopathy, IgA nephropathy, systemic lupus erythematosus, Alport syndrome/collagen IV glomerulopathy, amyloidosis, and thrombotic microangiopathy (TMA). Workup for these conditions should be considered especially in patients presenting with a reduced estimated GFR (eGFR) and may include kidney biopsy, 
Table 2 Initial workup and follow-up for a child with steroid-resistant nephrotic syndrome

Investigations

Initial workup

Follow-up monitoring

Clinical evaluation

Patient history

- Including results of dipstick assessments at home, physical activity, fever episodes, pain, abdominal discomfort, swelling, fatigue, school attendance, adherence to medication, menstrual cycle in female adolescents

- Search for risk factors for secondary causes (sickle cell disease, HIV, SLE, HepB, malaria, parvovirus B19)

- Check for tuberculosis in endemic areas before starting immunosuppressant drugs

Physical examination

- Assessing fluid status including signs of edema (e.g., ascites, pericardial \& pleural effusions), tetany, lymphadenopathy

- Drug toxicity (e.g., eyes, skin)

- Skeletal status

- Extrarenal features, e.g., dysmorphic features or ambiguous genitalia

Full neurological examination \& standardized assessment of cognitive status

Pubertal status: Tanner stage, testicular volume in boys (in patients aged $>10$ years)

Vital parameters: blood pressure

Anthropometry :

- Growth chart: height/length, weight,

- Head circumference $<2$ years

- Calculation of BMI and annual height velocity

Vaccination status

- Check and complete, especially for encapsulated bacteriapneumococcal, meningococcal, hemophilus influenza, and varicella-zoster if available

Family history

- Renal and extrarenal manifestations

- Consanguinity

Biochemistry

Urine

Spot urine (first morning void) or $24 \mathrm{~h}$ urine:

protein/creatinine

Urinalysis including hematuria

Spot urine: calcium/creatinine ratio, low molecular weight proteinuria (e.g., $\alpha_{1}$-microglobulin/creatinine ratio

Blood

Complete blood count (CBC)

Creatinine, BUN, or urea

Electrolytes (including ionized calcium, potassium*, and

albumin corrected albumin if available)

Serum albumin, total protein

Blood gas analysis $\left(\mathrm{HCO}_{3}\right)$

C-reactive protein

Estimated GFR ${ }^{\mathrm{b}}$

ALP, PTH, 25(OH) vitamin D

Lipid profile (LDL- and HDL-cholesterol, triglycerides)

Baseline coagulation tests (prothrombine time (INR), aPTT, fibrinogen, ATIII), detailed thrombophilic screening in patients with reported previous thrombotic events, central venous lines, persistent nephrotic range proteinuria, and/or increased familial history for thrombotic events
Every 3 months

As appropriate

As appropriate

Every 3 months

Every 3 months

Every 3 months

As appropriate

Every 12 months or as appropriate

Every 12 months

Every 3 months; yearly $24 \mathrm{~h}$ ambulatory BP monitoring in patients with hypertension, if feasible

Every 3 months (monthly in infants)

Every 12 month or as appropriate

Every 12 month or as appropriate

Every 3 months (more frequently until remission)

Essential $\checkmark$

Conditional

$\checkmark$

Essential
Every 3 months (more frequently until remission and in CKD stage 4-5)

Every day or every other day when using high dose diuretics

As required (clinical decision)

Every 3 months (more frequently in CKD stage 4)

Every 12 months (more frequently in patients with CKD stages 3-5)

Every 12 months or as appropriate

At diagnosis and then as appropriate, e.g., in case of relapses 
Table 2 (continued)

Investigations

Thyroid function (T3, FT4, TSH)

Immunoglobulin $\mathrm{G}$

Glucose/fasting glucose

$\mathrm{HbA1c}$

$\mathrm{C} 3$, antinuclear antibodies

ds-DNA, ENA, ANCA

HBs-Ag, anti-HCV-IgG, syphilis, and HIV tests

Vaccination status including blood titer tests

Genetics

Next-generation sequencing (NGS)/Whole Exome

Sequencing (WES)

Drug-specific monitoring

CsA and Tacrolimus: Drug trough levels

MMF: mycophenolic acid kinetic $(2 \mathrm{~h})^{\mathrm{c}}$

Rituximab

Statins: creatinine kinase (CK)

Prolonged glucocorticoid therapy

Imaging

Renal ultrasound: renal echogenicity and size of kidneys

Ultrasound of abdomen \& pleural space (ascites, effusions, thrombosis)

Cardiac ultrasound (left ventricular mass, effusions)

Chest X-ray

$\mathrm{X}$-ray of the left wrist (bone age assessment in children aged $>5$ years, mineralization)

Histopathology

Renal biopsy

\section{Dietary assessment}

Dietician review and advice by a dietician regarding salt, potassium, caloric and protein intake

Assessment for extrarenal involvement

Depending on underlying disease and clinically evident extrarenal features:

- Brain MRI (e.g., microcephaly, psychomotor delay, mental retardation, myoclonic epilepsy, tremor, ataxia, hypotonia)

- Interdisciplinary evaluation by Ophthalmology (e.g., microcoria, cataract, glaucoma, optic atrophy, keratoconus, macular spots, lenticonus, nystagmus),

- Cardiology (e.g., congenital heart defects),

Initial workup

Follow-up monitoring

$\checkmark$

$\checkmark$

$\checkmark$

$\checkmark$

$\checkmark$

Conditional

$\checkmark$

$\checkmark$

$\checkmark$

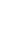

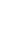

$-$

$-$

$-$

Conditional

$\checkmark$

$\checkmark$

$\checkmark$

$\checkmark$

Optional

$\checkmark$

(1)

$\checkmark$

If indicated
Every 12 months or as appropriate especially in patients with prolonged proteinuria

In case of recurrent infections

Every 6 months or as appropriate

Every 12 months or as appropriate

As appropriate

As appropriate

Before prednisolone and as appropriate

Yearly or as appropriate

Extended genetic screening for patients with SRNS depending on new findings (Table 3); whole exome sequencing if indicated

Before transplantation, if not previously performed

Weekly during titration period (for 4 weeks), thereafter every 3 months or as appropriate

AUC after 4 weeks of treatment, thereafter every 6-12 months or as appropriate

CD19 B cell count: baseline, 1 month after the first dose (nadir), every 1-3 months until B cell recovery

If on statins, every 6 months

Ophthalmological examination for cataract and intraocular pressure

Bone mineral density by lumbar DEXA

At presentation (mandatory prerenal biopsy)

as appropriate

Every 12 months in hypertensive patients or in case of severe edema

If indicated

Every 12 months or as appropriate

See text: at diagnosis, and subsequently if indicated: in case of unexplained drop in eGFR, unexplained increase in proteinuria, to rule out and/or to monitor CNI nephrotoxicity during prolonged $(<2$ years) treatment

Every 3 months (more frequently in infants, malnourished patients, and patients with CKD stage 4-5)

If indicated 
Table 2 (continued)

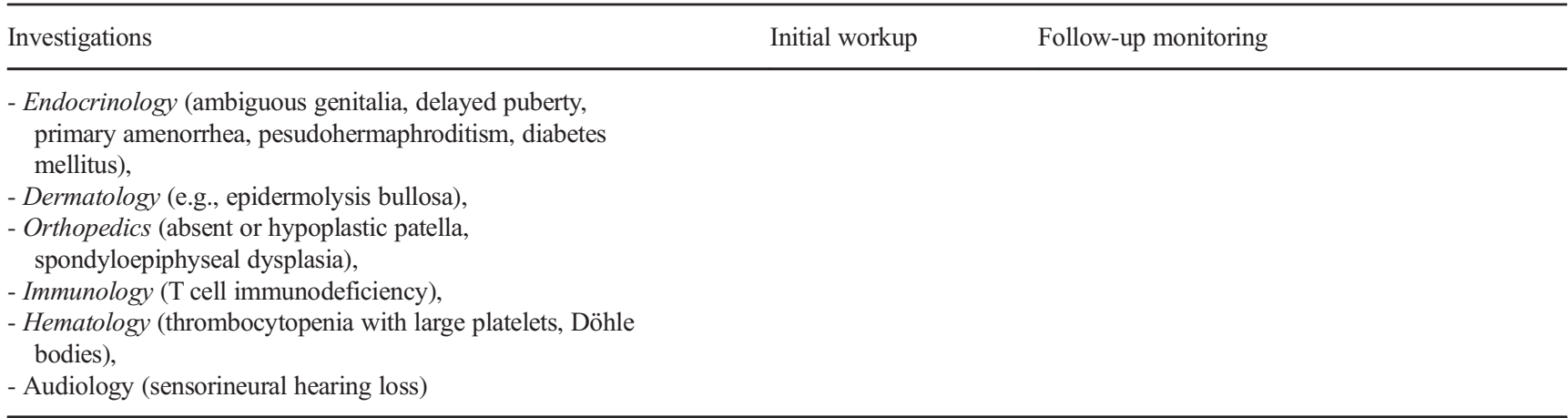

$A L P$ alkaline phosphatase, $P T H$ parathyroid hormone, $C N I$ calcineurin inhibitor, $C s A$ cyclosporine $\mathrm{A}, B P$ blood pressure, $M M F$ mycophenolate mofetil

${ }^{a}$ Anthropometric data should be compared with updated national or international (WHO charts [20]) standards

${ }^{\mathrm{b}}$ eGFR $\left(\mathrm{ml} / \mathrm{min} / 1.73 \mathrm{~m}^{2}\right)=k$ height $(\mathrm{cm}) /$ plasma creatinine $(\mathrm{mg} / \mathrm{dl})$; where $k$ is a constant $=0.413$. In malnourished or obese patients cystatin-based equations should be used [21]

${ }^{\mathrm{c}}$ According to Gellerman et al. [22]

genetic testing, and/or assessment of complement $\mathrm{C} 3, \mathrm{C} 4$, antinuclear antibodies, anti-streptococcal antibodies, and ANCA. Later in the disease course, a low eGFR may signal progression of disease, acute kidney injury (AKI), or drug toxicity. Renal ultrasound including Doppler evaluation assists with evaluation of congenital abnormalities of the kidney and urinary tract and vascular thrombosis, which can also be a cause of proteinuria. Given the $25 \%$ risk of disease in siblings if a patient has autosomal recessive SRNS, urinalysis is advisable for siblings.

\section{Indications for genetic testing and renal biopsy}

- We recommend, if available, that genetic testing be performed in all children diagnosed with primary SRNS (grade $\mathrm{B}$, moderate recommendation).

- We suggest giving priority to genetic testing in familial cases (family history of proteinuria/hematuria or CKD of unknown origin), cases with extra-renal features, and those undergoing preparation for renal transplantation (grade $\mathrm{C}$, weak recommendation).

- We recommend a kidney biopsy in all children diagnosed with SRNS, except in known infection or malignancyassociated secondary disease or potentially in patients with familial and/or syndromic cases or genetic causes of SRNS (grade A, strong recommendation).

- We suggest genetic testing before a kidney biopsy in children with SRNS, especially in priority cases (see above), provided the results will be readily available (within few weeks) (grade D, weak recommendation).

- We do not recommend performing genetic testing in patients with initial steroid sensitivity who subsequently develop steroid resistance later in their disease course (i.e., secondary steroid resistance) (grade $\mathrm{C}$, moderate recommendation).

\section{Evidence and rationale}

\section{Genetic testing}

Genetic testing in SRNS patients (i) may provide patients and families with an unequivocal diagnosis, (ii) may uncover a form of SRNS that is amenable to treatment (e.g., coenzyme Q10), (iii) may avoid the necessity of a renal biopsy and allow early weaning of immunosuppressive therapy, (iv) may allow accurate, well-informed genetic counseling including risk of recurrence post-transplantation [23, 24], and (v) may allow appropriate diagnosis and management of extrarenal manifestations $[25,26]$. With whole exome sequencing (WES) technology, 10-30\% of children are now diagnosed with a monogenic disease [8]. Mutations in NPHS2, WT1, and NPHS1 are the most common genetic SRNS causes in European patients, accounting for 42, 16, and $13 \%$ of genetic cases, respectively [26]. Mutations in the NPHS2 gene caused SRNS in $\sim 20-30 \%$ of sporadic Caucasian cases [23]. The likelihood of identifying a causative mutation is inversely related to age at disease onset and is increased with either a positive family history or the presence of extrarenal manifestations [27], but genes commonly implicated in one population may not be common in another population [28-30]. In patients with monogenic forms of SRNS, immunosuppressive treatment should be withdrawn since there is evidence supporting the ineffectiveness of this treatment [31].

\section{Renal biopsy}

Renal biopsy allows the exclusion of the other differential diagnoses listed above (e.g., membranous nephropathy) and the confirmation of a primary podocytopathy (MCD, FSGS, or DMS). Moreover, it allows the detection and grading of 
Table 3 Genes to be included in Next Generation Sequencing (from [8]) in a child with SRNS

\begin{tabular}{|c|c|c|c|}
\hline Gene & Inheritance & Accession no. & Disease \\
\hline ACTN4当 & $\mathrm{AD}$ & NM_004924 & Familial and sporadic SRNS (usually adult) \\
\hline$A D C K 4_{-}^{*}$ & $\mathrm{AR}$ & NM_024876 & SRNS \\
\hline$A L G 1$ & $\mathrm{AR}$ & NM_019109 & Congenital disorder of glycosylation \\
\hline$A N K F Y 1$ & $\mathrm{AR}$ & NM_001330063.2 & Pediatric SRNS \\
\hline$A N L N$ & $\mathrm{AD}$ & NM_018685 & FSGS (mainly adult) \\
\hline ARHGAP24 & $\mathrm{AD}$ & NM_001025616 & FSGS \\
\hline ARHGDIA & $\mathrm{AR}$ & NM_001185078 & CNS \\
\hline AVIL & AR & NM_006576.3 & SRNS \\
\hline$C D 151$ & $\mathrm{AR}$ & NM_004357 & $\begin{array}{l}\text { NS, pretibial bullous skin lesions, neurosensory } \\
\text { deafness, bilateral lacrimal duct stenosis, nail } \\
\text { dystrophy, and thalassemia minor }\end{array}$ \\
\hline$C D 2 A P$ & $\mathrm{AD} / \mathrm{AR}$ & NM_012120 & FSGS/SRNS \\
\hline $\mathrm{CFH}$ & $\mathrm{AR}$ & NM_000186 & MPGN type II + NS \\
\hline CLCN5 & $\mathrm{XR}$ & NM_001127898.4 & $\begin{array}{l}\text { Dent's disease } \pm \text { FSGS } \pm \text { hypercalcuria and } \\
\text { nepthrolithiasis }\end{array}$ \\
\hline$C O L 4 A 3_{-}^{*}$ & $\mathrm{AR}$ & NM_000091 & Alport's disease/FSGS \\
\hline COL $4 A 4$ & $\mathrm{AR}$ & NM_000092 & Alport's disease/FSGS \\
\hline COL4A5* & $\mathrm{XR}$ & NM_000495 & Alport's disease/FSGS \\
\hline COQ2 & $\mathrm{AR}$ & NM_015697 & Mitochondrial disease/isolated nephropathy \\
\hline COQ6 & $\mathrm{AR}$ & NM_182476 & $\mathrm{NS} \pm$ sensorineural deafness; DMS \\
\hline$C R B 2_{-}^{*}$ & $\mathrm{AR}$ & NM_173689 & SRNS \\
\hline$C U B N$ & $\mathrm{AR}$ & NM_001081 & Intermittent nephrotic range proteinuria \pm with epilepsy \\
\hline$D G K E_{-}^{*}$ & $\mathrm{AR}$ & NM_003647 & Hemolytic-uremic syndrome, SRNS \\
\hline$D L C 1$ & $\mathrm{AR}$ & NM_182643.3 & Childhood and adult SSNS and SRNS \\
\hline$E 2 F 3$ & $\mathrm{AD}$ & NM_001949 & FSGS + mental retardation (whole gene deletion) \\
\hline$E M P 2$ & $\mathrm{AR}$ & NM_001424 & Childhood-onset SRNS and SSNS \\
\hline FAT1 & $\mathrm{AR}$ & NM_005245.4 & $\begin{array}{l}\text { Combination of SRNS, tubular ectasia, hematuria, and } \\
\text { facultative }\end{array}$ \\
\hline FN1 & $\mathrm{AD} ?$ & NM_212482.3 & Fibronectin glomerulopathy \\
\hline GAPVD1 & $\mathrm{AR}$ & NM_001282680.3 & Early-onset NS \\
\hline$I N F 2$ & $\mathrm{AD}$ & NM_022489 & $\begin{array}{l}\text { Familial and sporadic SRNS, FSGS-associated } \\
\text { Charcot-Marie-Tooth neuropathy }\end{array}$ \\
\hline ITGA3 & $\mathrm{AR}$ & NM_002204 & $\begin{array}{l}\text { Congenital interstitial lung disease, nephrotic } \\
\text { syndrome, and mild epidermolysis bullosa }\end{array}$ \\
\hline ITGB4 & $\mathrm{AR}$ & NM_000213 & Epidermolysis bullosa and pyloric atresia + FSGS \\
\hline ITSN1 & $\mathrm{AR}$ & NM_003024.3 & CNS/SRNS/SSNS (with MCD/FSGS on biopsy) \\
\hline ITSN2 & $\mathrm{AR}$ & NM_019595.4 & SSNS/SDNS (with MCD/MPGN on biopsy) \\
\hline KANK1 & $\mathrm{AR}$ & NM_015158 & SSNS \\
\hline KANK2 & $\mathrm{AR}$ & NM_015493 & SSNS/SDNS \pm hematuria \\
\hline KANK4 & $\mathrm{AR}$ & NM_181712 & SRNS + hematuria \\
\hline KIRREL1 & $\mathrm{AR}$ & NM_018240.7 & SRNS \\
\hline$L A G E 3$ & $\mathrm{AR}$ & NM_006014.4 & NS with primary microcephaly \\
\hline LAMA5 & AR & NM_005560.6 & Childhood NS \\
\hline$L A M B 2_{-}^{*}$ & $\mathrm{AR}$ & NM_002292 & Pierson syndrome \\
\hline$L C A T$ & $\mathrm{AR}$ & NM_000229.2 & Norum disease \\
\hline LMNA & $\mathrm{AD}$ & NM_170707 & Familial partial lipodystrophy + FSGS \\
\hline$L M X 1 B_{-}^{*}$ & $\mathrm{AD}$ & NM_002316 & $\begin{array}{l}\text { Nail patella syndrome; also FSGS without extrarenal } \\
\text { involvement }\end{array}$ \\
\hline$M A F B$ & $\mathrm{AD}$ & NM_005461.5 & FSGS with Duane retraction syndrome \\
\hline MAGI2 & $\mathrm{AR}$ & NM_012301.4 & $\mathrm{NS} \pm$ neurological impairment \\
\hline
\end{tabular}


Table 3 (continued)

\begin{tabular}{|c|c|c|c|}
\hline Gene & Inheritance & Accession no. & Disease \\
\hline MMACHC & $\mathrm{AR}$ & NM_015506.3 & $\begin{array}{l}\text { Cobalamin C deficiency, TMA, and nephrotic } \\
\text { syndrome }\end{array}$ \\
\hline$M Y O 1 E_{-}^{*}$ & $\mathrm{AR}$ & NM_004998 & Familial SRNS \\
\hline NEU1 & AR & NM_000434.4 & Nephrosialidosis (sialidosis type II + childhood NS) \\
\hline NPHP4 & $\mathrm{AR}$ & NM_015102.5 & $\begin{array}{l}\text { Nephronophthisis with FSGS and nephrotic range } \\
\text { proteinuria }\end{array}$ \\
\hline $\mathrm{NPHSI}_{-}^{*}$ & $\mathrm{AR}$ & NM_004646 & CNS/SRNS \\
\hline $\mathrm{NPHS2}_{-}^{*}$ & AR & NM_014625 & CNS, SRNS \\
\hline NUP85 & AR & NM_024844.5 & SRNS \\
\hline NUP93* & AR & NM_014669 & Childhood SRNS \\
\hline NUP107* & AR & NM_020401 & Childhood SRNS \\
\hline NUP160 & AR & NM_015231.2 & SRNS \\
\hline NUP205 & AR & NM_015135 & Childhood SRNS \\
\hline NXF5 & $\mathrm{XR}$ & NM_032946 & FSGS with co-segregating heart block disorder \\
\hline$O C R L_{-}^{*}$ & $\mathrm{XR}$ & NM_000276 & $\begin{array}{l}\text { Dent's disease- } 2 \text {, Lowe syndrome, } \pm \text { FSGS }, \pm \\
\text { nephrotic range proteinuria }\end{array}$ \\
\hline OSGEP & $\mathrm{AR}$ & NM_017807.4 & NS with primary microcephaly \\
\hline$P A X 2$ & $\mathrm{AD}$ & NM_003987 & Adult-onset FSGS without extrarenal manifestations \\
\hline PDSS2 & AR & NM_020381 & Leigh syndrome \\
\hline PLCel & AR & NM_016341 & CNS/SRNS \\
\hline$P M M 2$ & AR & NM_000303 & Congenital disorder of glycosylation \\
\hline$P O D X L_{-}^{*}$ & $\mathrm{AD}$ & NM_005397 & FSGS \\
\hline PTPRO & $\mathrm{AR}$ & NM_030667 & NS \\
\hline$S C A R B 2$ & $\mathrm{AR}$ & NM_005506 & $\begin{array}{l}\text { Action myoclonus renal failure syndrome } \pm \text { hearing } \\
\text { loss }\end{array}$ \\
\hline$S G P L 1$ & $\mathrm{AR}$ & NM_003901.4 & Primary adrenal insufficiency and SRNS \\
\hline SMARCAL1 & AR & NM_014140 & Schimke immuno-osseous dysplasia \\
\hline SYNPO & $\mathrm{AD}$ & NM_007286 & Sporadic FSGS (promoter mutations) \\
\hline$T B C 1 D 8 B$ & $\mathrm{XR}$ & NM_017752.3 & Early-onset SRNS with FSGS \\
\hline TNS2 & $\mathrm{AR}$ & NM_170754.3 & SSNS/SDNS (with MCD/FSGS/DMS on biopsy) \\
\hline TP53RK & AR & NM_033550.4 & NS with primary microcephaly \\
\hline TPRKB & $\mathrm{AR}$ & NM_001330389.1 & NS with primary microcephaly \\
\hline TRPC6 & $\mathrm{AD}$ & NM_004621 & Familial and sporadic SRNS (mainly adult) \\
\hline TTC21B & $\mathrm{AR}$ & NM_024753 & FSGS with tubulointerstitial involvement \\
\hline WDR73 & $\mathrm{AR}$ & NM_032856 & Galloway-Mowat syndrome (microcephaly and SRNS) \\
\hline$W T 1_{-}^{*}$ & $\mathrm{AD}$ & NM_024426 & $\begin{array}{l}\text { Sporadic SRNS (children: may be associated with } \\
\text { abnormal genitalia); Denys-Drash and Frasier } \\
\text { syndrome }\end{array}$ \\
\hline XPO5 & $\mathrm{AR}$ & NM_020750 & Childhood SRNS \\
\hline ZMPSTE24 & AR & NM_005857 & Mandibuloacral dysplasia with FSGS \\
\hline МYH9 & $\mathrm{AD} / \mathrm{assoc}$ & NM_002473 & $\begin{array}{l}\text { MYH9-related disease; Epstein and Fechtner } \\
\text { syndromes }\end{array}$ \\
\hline$A P O L 1_{-}^{*}$ & $\mathrm{G} 1, \mathrm{G} 2$ risk alleles & NM_003661 & $\begin{array}{l}\text { Increased susceptibility to FSGS and ESRD in African } \\
\text { Americans, Hispanic Americans and in individuals } \\
\text { of African descent }\end{array}$ \\
\hline
\end{tabular}

$A D$ autosomal dominant, $A R$ autosomal recessive, $C N S$ congenital nephrotic syndrome, $D M S$ diffuse mesangial sclerosis, $E S R D$ end-stage renal disease, FSGS focal segmental glomerulosclerosis, MPGN membranoproliferative glomerulonephritis, $N S$ nephrotic syndrome, SDNS steroid-dependent nephrotic syndrome, SRNS steroid resistant nephrotic syndrome, SSNS steroid sensitive nephrotic syndrome

*Genes with a likely or known mutation, or a risk allele, in this cohort 
tubular atrophy, interstitial fibrosis, and glomerulosclerosis as prognostic markers $[32,33]$. Therefore, once a child is defined as having SRNS, a renal biopsy should be performed according to current standards as described in Supplementary Material to determine the underlying pathology before initiating treatment with CNI, unless a clear monogenic form of SRNS known to be unresponsive to immunosuppression is identified. This is particularly relevant in settings where access to genetic testing is limited.

\section{Genetic testing and counseling}

- We recommend comprehensive gene panel analysis (i.e., a next generation sequencing panel to include all currently known SRNS genes, which is currently the most costeffective approach to genetic testing) (genes are listed in Table 3) unless the clinical phenotype is suggestive of a specific condition, in which case we suggest performing a single gene analysis instead (grade B, moderate recommendation).

- We suggest determining the pathogenicity of identified genetic variants according to the guidelines of the American College of Medical Genetics [34]. Family segregation analysis may be performed in selected cases (grade B, moderate recommendation).

- We recommend genetic counseling for patients and their families to help them interpret both anticipated and unanticipated genetic findings (grade B, moderate recommendation).

\section{Evidence and rationale}

We recommend performing genetic testing according to current standards $[24,35]$. This includes confirmation of pathogenic or likely pathogenic variants by Sanger sequencing. In cases where no causative mutations are found in known gene panels, whole exome sequencing or whole genome sequencing may be considered, especially if the suspicion of a genetic etiology is high. Caution and expertise are required in interpreting variants of unknown significance [36]. Without genetic counseling patients and their families may not understand the significance of genetic findings [37].

\section{Screening for infections}

- We recommend evaluation for subclinical tuberculosis according to country-specific guidelines (i.e., chest radiography, tuberculin test, quantiferon assay), if clinically suspected, or in case of residence in or travel from endemic areas (grade $\mathrm{C}$, moderate recommendation).
- We suggest testing for hepatitis B, C, syphilis, and HIV: (i) to rule out secondary causes of NS and (ii) before immunosuppression, especially rituximab, given the endemicity of these infections in various countries (grade $\mathrm{C}$, weak recommendation).

\section{Evidence and rationale}

Accounting for country-specific disease prevalence and individual risk assessment, evaluations for infections causing secondary forms of SRNS should be completed.

\section{Treatment}

\section{First-line non-immunosuppressive treatment in children with SRNS}

- We recommend starting RAASi with either angiotensin converting enzyme inhibitors (ACEi) or angiotensin receptor blockers (ARBs) once the diagnosis of SRNS is made (Fig. 2) (grade B, moderate recommendation).

- We suggest quantifying the change in first-morning proteinuria after starting RAASi therapy (grade D, weak recommendation).

- We suggest aiming for the maximum approved dosages given in Table S8 as tolerated (grade C, weak recommendation).

- ACEi or ARBs should be used with caution in patients with CKD stage 4, and they should not be started or should be stopped in case of intravascular volume depletion, acute kidney injury (AKI), hyperkalemia, or frequent vomiting/diarrhea (grade $\mathrm{X}$, strong recommendation).

- We suggest using RAASi with non-renal metabolism (i.e., ramipril and ARBs) since they do not accumulate in renal failure (grade D, weak recommendation).

- In female adolescents, contraception should be ensured in order to avoid the teratogenic effects of RAASi (grade X, strong recommendation).

\section{Evidence and rationale}

In CKD patients RAAS blockade by ACEi or ARBs decreases intraglomerular pressure, decelerates progression of CKD, and reduces proteinuria [38-42]. We recommend aiming for the maximum approved dosages as tolerated since dosedependent antiproteinuric effects of ACEi with reductions of $\sim 30 \%$ are expected [39]. Complete remissions have been reported in children with SRNS after therapy with ACEi or ARBs without additional medications other than PDN [43]. 
Therefore, in children with confirmed or suspected SRNS, this treatment may be commenced as early as 4 weeks from PDN initiation, during the so-called confirmation period. However, ACEi/ARBs may increase the risk for AKI, especially in patients with advanced CKD or intravascular volume depletion $[44,45]$. Combined treatment with ACEi and ARBs is discouraged due to the increased risk for adverse events including AKI and death [46]. Agents with non-renal metabolism should be preferred since they do not accumulate in CKD (Table S8) [44]. Contraception is essential in female adolescents to avoid RAAS blocker fetopathy [47].

\section{First-line immunosuppressive treatment in children with SRNS}

- We recommend that CNI (cyclosporine or tacrolimus) should be the first-line immunosuppressive therapy in children with SRNS and started once the diagnosis is confirmed (Fig. 2) (grade B, moderate recommendation).

- We suggest tapering PDN treatment once diagnosis of SRNS is established and discontinuing PDN therapy after 6 months (grade $\mathrm{D}$, weak recommendation).

- We recommend withholding or delaying CNI treatment in patients with an eGFR $<30 \mathrm{ml} / \mathrm{min} / 1.73 \mathrm{~m}^{2}$, AKI, and/or uncontrolled hypertension (grade X, strong recommendation).

- We recommend withholding CNI and stopping PDN treatment in patients with evidence for a monogenic form of SRNS (grade B, moderate recommendation).

- When CNIs are not available or unaffordable, we suggest using cyclophosphamide $(\mathrm{CPH})$ [intravenous or po] with or without high-dose steroids (grade D, weak recommendation).

- We recommend making patients and families aware of potential side effects of immunosuppressive medication as given in Table 4 (grade $\mathrm{X}$, strong recommendation).

\section{Evidence and rationale}

\section{Calcineurin inhibitors}

The use of CNI as first-line therapy in children with SRNS was assessed in 8 RCTs comparing the efficacy of cyclosporine (CsA) with either placebo [48], no treatment [49, 50], intravenous MPDN [51], MMF with dexamethasone [52], or tacrolimus (TAC) [53, 54], and CsA or TAC with intravenous $\mathrm{CPH}[55,56]$, on the outcome of "number with complete or partial remission" (Supplementary Table S2). CsA compared with placebo, no treatment, or intravenous MPDN showed superior outcome $(\sim 75 \%$ vs. $22 \%)$ irrespective of histopathology (risk ratio 3.50 (95\% CI 1.04-9.57) [14]. There was no difference in outcome when TAC was compared with CsA (risk ratio 1.05 [95\% CI 0.87-1.25]) [14, 53, 54]. CsA or TAC was more effective than intravenous $\mathrm{CPH}$ (78\% vs. $40 \%$; risk ratio 1.98 [95\% CI 1.25-3.13]) [55, 56]. CsA compared with MMF in combination with dexamethasone was similarly effective ( $46 \%$ vs. $33 \%$; risk ratio 1.38 [95\% CI 0.9-2.10] [52]. TAC was more effective when compared with MMF in order to maintain remission (90\% vs. $45 \%$; risk ratio 2.01 [95\% CI 1.32-3.07) [57]. When CsA was compared with placebo, no treatment, or MPDN, no differences were detected in the number of patients developing ESKD but event numbers were very small $[48,51,58]$. When CNIs were compared with intravenous $\mathrm{CPH}$, there was an increase in serious adverse effects with $\mathrm{CPH}$, but there were no differences in persistent nephrotoxicity or death [55]. No differences were detected in comparisons of CsA, MMF + dexamethasone, or TAC in terms of outcomes of ESKD, or $50 \%$ decline in eGFR $[52,53,55,57]$.

Treatment with CNIs is discouraged in patients with reduced eGFR, AKI, and/or uncontrolled hypertension due to their nephrotoxic effects. However, in patients with chronic CKD and no other option for disease control, CNIs may improve proteinuria and long-term kidney survival [59].

SRNS patients who do not show at least partial remission to CNI by 6 months are deemed CNI resistant, and those who do not respond to CNI plus another agent that is mechanistically distinct by 12 cumulative months of therapy as multi-drug resistant (vide supra). If a monogenic form of SRNS known not to respond to immunosuppression is identified in a patient and no response to immunosuppression has previously been observed in the patient, then immunosuppression should be discontinued. We suggest that patients in these categories remain off immunosuppression but continue on RAASi therapy until they reach advanced stages of CKD and can no longer tolerate RAASi (Fig. 2).

\section{Alkylating agents and low resource settings}

When compared with PDN/placebo, CPH showed no difference in the outcome of complete remission (risk ratio $1.0695 \%$ CI 0.61-1.87) [60, 61]. Overall, 36\% children on $\mathrm{CPH}$ compared with $35 \%$ on PDN achieved complete remission [60]. Similar remission rates were noted in patients receiving intravenous or oral $\mathrm{CPH}$ (each $\sim 50 \%$ ) [14, 62-64]. The response to $\mathrm{CPH}$ reported in some observational studies may indicate a certain overlap of SSNS and SRNS $[65,66]$. Older studies may have included children with monogenic causes of NS, given that genetic testing was not commonly available for patients before 20002010 resulting in low response rates to $\mathrm{CPH}$. CPH may be trialed to induce remission in resource-limited settings, 
Table 4 Common medication-related complications and side effects to be assessed for patient monitoring

\begin{tabular}{|c|c|c|}
\hline Type of drug & Common medication-related side effect & Prevention \\
\hline All & Recurrent infections (bacterial, viral, fungal) & $\begin{array}{l}\text { Adequate but minimal dosing of } \\
\text { immunosuppressive medication } \\
\text { Vaccination (if feasible) }\end{array}$ \\
\hline Glucocorticoids & $\begin{array}{l}\text { Cushing syndrome } \\
\text { Hypertension } \\
\text { Glucose intolerance } \\
\text { Growth retardation } \\
\text { Reduced bone mineral density } \\
\text { Cataracts, glaucoma } \\
\text { Behavioral problems }\end{array}$ & $\begin{array}{l}\text { Careful use of glucocorticoids } \\
\text { No prolonged treatment } \\
\text { Use of steroid-sparing agents }\end{array}$ \\
\hline $\mathrm{CNI}$ & $\begin{array}{l}\text { Hypertension } \\
\text { Nephrotoxicity } \\
\text { Neurotoxicity (tremor) } \\
\text { Leg cramps } \\
\text { Hypomagnesemia } \\
\text { Interaction with other drugs }\end{array}$ & $\begin{array}{l}\text { Adequate but minimal dosing of } \\
\text { immunosuppressive medication, adapted } \\
\text { by drug monitoring. Dose reduction in } \\
\text { case of significant side effects }\end{array}$ \\
\hline Tacrolimus-specific: & Glucose intolerance and diabetes mellitus & \\
\hline Cyclosporine A-specific: & $\begin{array}{l}\text { Hypertrichosis } \\
\text { Gingival hyperplasia }\end{array}$ & \\
\hline \multirow[t]{2}{*}{ MMF } & $\begin{array}{l}\text { Hematology: } \\
\text { - Leukopenia/neutropenia } \\
\text { - Pancytopenia } \\
\text { Gastrointestinal intolerance (nausea, vomiting, } \\
\quad \text { abdominal pain, diarrhea) } \\
\text { Weight loss }\end{array}$ & $\begin{array}{l}\text { Adequate but minimal dosing of } \\
\text { immunosuppressive medication, adapted } \\
\text { by drug monitoring }\end{array}$ \\
\hline & $\begin{array}{l}\text { Dermatological problems: } \\
\text { - Verrucae } \\
\text { - Neoplasm of the skin } \\
\text { Neurological: } \\
\text { - Headaches } \\
\text { - Paraesthesia- Leg cramps }\end{array}$ & Additional sun/UV protection \\
\hline \multirow[t]{3}{*}{ RITUXIMAB } & $\begin{array}{l}\text { - Hep. B and fulminant hepatitis } \\
\text { Specific Infections }\end{array}$ & - Pneumocystis jirovecii pneumonia \\
\hline & $\begin{array}{l}\text { Prophylaxis with cotrimoxazole } \\
\text { Hypogammaglobulinemia } \\
\text { Leukopenia/neutropenia } \\
\text { Pancytopenia }\end{array}$ & Hepatitis B vaccination \\
\hline & $\begin{array}{l}\text { Acute infusion reactions } \\
\text { - Angioedema } \\
\text { - Bronchospasm, } \\
\text { - Urticaria } \\
\text { Progressive multifocal leukoencephalopathy } \\
\text { (PML), induced by JC-Virus }\end{array}$ & Premedication \\
\hline
\end{tabular}

but should be stopped in case of achieving no-response. Since chlorambucil was not evaluated in any RCTs, we make no suggestions for its use.

\section{CNI schedule, monitoring, and co-interventions}

- We suggest a starting CsA dose of 3-5 mg/kg/day (max starting $250 \mathrm{mg} /$ day) given orally twice daily (grade B, weak recommendation).

- We suggest titrating the CsA dosage in at least daily intervals aiming for CsA whole blood trough levels between 80 and $120 \mathrm{ng} / \mathrm{ml}$ based on assays validated against tandem mass spectrometry (grade B, weak recommendation).

- We suggest a TAC starting dose of $0.1-0.2 \mathrm{mg} / \mathrm{kg} /$ day (max starting $5 \mathrm{mg} /$ day) given orally twice daily (grade $\mathrm{B}$, weak recommendation).

- We suggest titrating the TAC dose aiming for trough levels between 4 and $8 \mathrm{ng} / \mathrm{ml}$. We also suggest titration intervals of at least 3 days (grade B, weak recommendation).

- We suggest monitoring CsA/TAC trough levels at least weekly until target levels are reached, and then every 13 months together with serum creatinine as a safety parameter (grade $\mathrm{D}$, weak recommendation) (Table 2 ). 
- We recommend reducing CNI dosage or its withdrawal if eGFR decreases below $30 \mathrm{ml} / \mathrm{min} / 1.73 \mathrm{~m}^{2}$ (grade $\mathrm{X}$, strong).

\section{Evidence and rationale}

Although monitoring of CsA at $2 \mathrm{~h}$ post dose (C2) is the most accurate single time point for assessment for therapeutic level [67], C2 target levels in SRNS patients are not widely established or practical for routine use. Instead, whole blood trough measurements by tandem mass spectrometry are recommended. These assays give lower readings than immunoassays, which were previously used. The ranges of CsA levels reported in RCTs vary widely [48, 49, 52, 53, 56, 58]. More recent studies use lower levels of CsA (troughs of 80 $150 \mathrm{ng} / \mathrm{ml}$ ), with an initial starting dose of $5-6 \mathrm{mg} / \mathrm{kg} /$ day [53-55, 57]. Since, even low CsA trough levels can be associated with long-term nephrotoxicity in children with NS, we suggest targeting CsA trough levels of $80-120 \mathrm{ng} / \mathrm{ml}$, although higher levels may be more effective but should be analyzed together with serum creatinine as a safety parameter. High dosages of CsA (C2 levels $>600 \mathrm{ng} / \mathrm{ml}$ ) showed increased risk for CsA nephrotoxicity especially when given in combination with ACEis/ARBs in children with SDNS [68]. Levels should be monitored weekly until steady state and then every $1-3$ months.

\section{Duration of CNI treatment}

- We suggest a minimum treatment period of 6 months to determine the response to CNIs (grade B, weak recommendation).

- We recommend that CNIs should be stopped if partial remission is not achieved at 6 months (grade $\mathrm{B}$, moderate recommendation).

- If complete remission is achieved, CNI dosages should be reduced to the lowest dosage required to maintain remission. We also suggest considering discontinuation of CNIs after 12-24 months in these patients to reduce the risk of nephrotoxicity (grade $\mathrm{C}$, weak recommendation). In these patients, switching to MMF can be considered to minimize nephrotoxicity and maintain remission (vide infra).

- If relapses occur after CNI discontinuation, we suggest restarting patients on CNIs for a trial together with 4 weeks of high-dose oral PDN. Alternately MMF or may be considered (grade $\mathrm{C}$, weak recommendation).

- If partial remission is achieved, we suggest continuing $\mathrm{CNI}$ at the same dosage for a minimum of 12 months (grade $\mathrm{C}$, weak recommendation).

\section{Evidence and rationale}

Due to the risk of nephrotoxicity and side effects related to long-term immunosuppression (see Table 4), CNIs should be discontinued after 6 months if at least a partial remission is not achieved. If complete remission is achieved, we suggest considering discontinuation of CNIs after 12-24 months. See "Treatment of relapse" for relapse therapy.

\section{Mycophenolate mofetil}

- If immunosuppression is considered in a child with SRNS and an eGFR $<30 \mathrm{ml} / \mathrm{min} / 1.73 \mathrm{~m}^{2}$, we suggest that MMF rather than CNIs be used due to the risk for nephrotoxicity with CNI (grade $\mathrm{C}$, weak recommendation).

- We suggest considering the use of MMF to maintain remission in children with SRNS in remission following $\mathrm{CNI}$ if they develop a steroid sensitive relapse (grade C, weak recommendation).

- In patients with SRNS who have attained full remission on CNI therapy for at least 12 months, we suggest considering conversion to MMF as an alternative immunosuppressive agent rather than continuing CNIs (grade $\mathrm{C}$, weak recommendation).

\section{Evidence and rationale}

If immunosuppression is considered in a child with SRNS and an eGFR $<30 \mathrm{ml} / \mathrm{min} / 1.73 \mathrm{~m}^{2}$, then MMF may be used to avoid CNI nephrotoxicity. CsA was not superior in achieving remission when compared with MMF in combination with dexamethasone (45\% vs. 33\%) [52]. When a child with SRNS achieves remission following CNI therapy but subsequently has a steroid sensitive relapse, then based on RCTs evaluating MMF in relapsing SSNS [22, 69, 70], MMF may be used to maintain remission. The rationale to switch to a CNIfree immunosuppressive protocol is to avoid long-term CNI toxicity. A CNI-to-MMF conversion protocol was applied successfully in children with SRNS after a mean of 1.7 years of CNI therapy with regular drug monitoring [71]. However, in an RCT conversion from TAC to MMF was shown to be inferior to maintain remission in patients achieving remission by TAC [57]. We suggest a MMF starting dose of $1200 \mathrm{mg} / \mathrm{m}^{2}$ per day, and performing therapeutic drug monitoring in SRNS patients aiming for a mycophenolic acid exposure (AUC) $>50 \mu \mathrm{g} \times$ $\mathrm{h} / \mathrm{ml}$ based on the results in SSNS patients [22].

\section{Repeat kidney biopsy}

- If there is an unexplained drop in eGFR or increase in proteinuria during follow-up, we suggest considering a 
repeat kidney biopsy for assessment of CNI nephrotoxicity (grade $\mathrm{C}$, weak recommendation).

- We suggest considering a renal biopsy in those patients who have prolonged CNI exposure ( $>2$ years) or when being restarted on CNI-treatment for a second course (grade $\mathrm{C}$, weak recommendation).

\section{Evidence and rationale}

An unexplained eGFR decrease or an increase in proteinuria may be due to disease progression or drug toxicity, especially in patients on long-term CNI treatment. The latter is supported in the presence of arteriolar hyalinization and smooth muscle vacuolization, ischemic glomerular collapse, juxtaglomerular apparatus hyperplasia, (striped) interstitial fibrosis and tubular atrophy on light microscopy, and mitochondrial damage on transmission electron microscopy [72].

\section{Co-intervention with glucocorticoids}

- We do not recommend prolonged (>6 months) routine PDN treatment in conjunction with CNI and RAASi (grade $\mathrm{C}$, moderate recommendation)

- We suggest tapering PDN after CNI initiation as follows: $40 \mathrm{mg} / \mathrm{m}^{2}$ QOD for 4 weeks, $30 \mathrm{mg} / \mathrm{m}^{2}$ QOD for 4 weeks, $20 \mathrm{mg} / \mathrm{m}^{2}$ QOD for 4 weeks, $10 \mathrm{mg} / \mathrm{m}^{2}$ QOD for 8 weeks, and discontinuing thereafter (grade D, weak recommendation).

\section{Evidence and rationale}

Prednisone was used as a co-intervention in several RCTs [52, $53,55,56]$. The dose and duration of PDN ranged from $1 \mathrm{mg} / \mathrm{kg} /$ day for 6 months QOD to $0.3 \mathrm{mg} / \mathrm{kg} /$ day for 6 months. There is no evidence that prolonged treatment with oral PDN is beneficial in SRNS patients but may cause steroid toxicity; therefore, we suggest a gradual reduction of PDN using the regimen suggested above, [73, 74]. PDN may be weaned off more quickly especially in patients presenting with glucocorticoid toxicity. However, this does not apply to a proportion of SRNS patients who achieve complete remission with CNI and subsequently behave as SDNS patients. These patients may be treated accordingly with additional low-dose alternate day oral PDN.

\section{Second-line approaches}

- Patients with SRNS who fail to achieve at least partial remission with CNIs (and who do not have genetic or syndromic disease) should be approached for participation in a clinical trial evaluating novel potential therapies for SRNS (ungraded).

- If a clinical trial is not available, the use of rituximab may be considered (grade $\mathrm{C}$, weak recommendation).

- We suggest administering two rituximab infusions at a dose of $375 \mathrm{mg} / \mathrm{m}^{2}$ per infusion in order to reduce the CD19 cell count below 5 per microliter or $1 \%$ (usually 1-2 infusions within 2 weeks) (grade $\mathrm{C}$, weak recommendation).

- Rituximab should not be given in the presence of tuberculosis, hepatitis B, or JC virus infections. In case of clinical suspicion and endemic background, patients should undergo screening by a chest X-ray, tuberculosis skin or blood test, HBs-Ag serology in case of elevated liver enzymes, and spinal fluid examination in case of neurological symptoms suggesting JC virus infection before commencing rituximab (grade $\mathrm{X}$, strong recommendation).

- In rituximab-resistant or rituximab-intolerant patients, the use of ofatumumab and extracorporeal blood purification therapies such as plasma exchange, immunoadsorption, or lipid apheresis may be considered (grade C, weak recommendation)

\section{Evidence and rationale}

Observational studies showed complete remissions in $\sim 30 \%$ of patients treated with rituximab as a rescue therapy for multidrug-resistant SRNS [75-85]. However, rituximab was not superior compared with treatment protocols including plasma exchange and immunoadsorption [85]. In most studies, patients with multidrug-resistant SRNS received rituxi$\mathrm{mab}$ at a dose of $375 \mathrm{mg} / \mathrm{m}^{2}$ per infusion, and 1-2 infusions over 2 weeks were usually sufficient to reduce the CD19 cell count below 5 per microliter or $1 \%$ of lymphocyte count. In patients achieving partial or complete remission, first-AM proteinuria and B cell counts should be monitored and a second course of rituximab be administered when proteinuria increases substantially after B cell reconstitution (CD19 cell count $>5$ per microliter or $1 \%$ of lymphocyte count). Contraindications for rituximab include hepatitis B, tuberculosis, or JC virus infections. Cotrimoxazole prophylaxis and completion of age appropriate vaccination schedule is recommended (see sections Antibiotic prophylaxis and Vaccination). Serum levels of IgG should be monitored after rituximab treatment as they were found to be low in $\sim 30 \%$ of patients $[86,87]$.

In several small pediatric studies, rituximab-resistant or rituximab-intolerant cases as well as patients without rituximab pretreatment reportedly underwent complete remission with the alternative CD20 cell-depleting agent ofatumumab 
[88-90]. Ofatumumab was administered in two studies at an initial dose of $300 \mathrm{mg} / 1.73 \mathrm{~m}^{2}(\max 300 \mathrm{mg})$ followed by 5 weekly doses of $2000 \mathrm{mg} / 1.73 \mathrm{~m}^{2}(\max 2000 \mathrm{mg})$ [89, 90] and in a single case report $750 \mathrm{mg} / 1.73 \mathrm{~m}^{2}$ [88].

Various pharmacological and extracorporeal therapies have been applied experimentally in patients with multidrug resistant SRNS. Partial or complete remission has been observed in individual case reports or in a few cases within small series of patients receiving plasmapheresis, plasma exchange, immunoadsorption, lipid apheresis [91-93], the B7-1 inhibitor abatacept [94-96], and oral galactose [97-99]. Inclusion of patients in clinical trials testing these and other novel therapies is strongly encouraged (ongoing studies are listed here: https:// kidneyhealthgateway.com/trials-research/).

\section{Withdrawing immunosuppression in non-responsive patients}

- We recommend that screening for all known podocytopathy genes be offered to enable decisions on further immunosuppression (grade X, strong recommendation).

- We recommend counseling patients and parents regarding the high risk of progression to ESKD in patients with hereditary forms and/or multidrug-resistant SRNS (grade $\mathrm{X}$, strong recommendation).

- We recommend discontinuing ineffective immunosuppressive therapies, and continuing nonimmunosuppressive management, including RAASi and other supportive measures (grade X, strong recommendation).

- In patients with non-genetic disease, we suggest exploring available options for novel therapies being assessed in clinical trials (grade $\mathrm{X}$, strong recommendation).

- In patients with inherited defects who have achieved partial or complete remission with immunosuppression, we suggest the following:

The genetic variant(s) should be reviewed to confirm whether it is indeed pathogenic or likely pathogenic (grade A, strong recommendation).

A decision to continue or discontinue immunosuppression should follow parental counseling regarding the anticipated benefits of remission (symptomatic relief; potentially lower risk of disease progression) versus the potential risks (therapy related toxicity; infections) and cost of therapy (grade A, strong recommendation).

\section{Evidence and rationale}

Non-response is associated with rapid progression to ESKD [11, 100, 101]. In patients with genetic forms of
SRNS, low rates of complete $(2.7-3.0 \%)$ or partial response $(10.8-16 \%)$ to immunosuppression were reported [9, 11, 101, 102]. Patients with genetic forms of SRNS progress to ESKD more often than those without inherited defects (71-74\% vs. 4-29\%) and show shorter median renal survival (45-48 months vs. 58-205 months) [11, 100-102]. Given the likelihood of harm versus benefit, we suggest withdrawing immunosuppression in nonresponsive monogenic SRNS patients. In those with defects in the COQ pathway, COQ10 supplementation may be considered [103-105]. While the probability of response to experimental therapies is low in patients with multi-drug-resistant disease, therapy could be contemplated after direct counseling of patients and parents about the low likelihood of benefit, and the possibility of toxicity with such therapies [89, 91, 106-108].

\section{Additional measures to reduce symptoms and control edema}

Salt

- We suggest that excessive salt intake should be avoided in children with SRNS (Table S11) (grade C, weak recommendation).

- When available, a dietician should provide advice to patients and families on suitable low-salt foods and on the high-salt foods to avoid (grade D, weak recommendation).

Fluid

- We do not recommend routine fluid restriction in SRNS patients (grade $\mathrm{C}$, weak recommendation).

- We suggest a balanced fluid intake taking into account the urine output, volume status, and serum sodium (grade C, weak recommendation).

\section{Diuretics}

- We suggest considering treatment with loop diuretics (e.g., furosemide) in patients with severe edema. In patients with refractory edema, the addition of metolazone, thiazides, or potassium sparing diuretics may also be considered (grade C, moderate recommendation).

- Diuretics should not be given to patients with signs of intravascular volume depletion including prolonged capillary refill time, tachycardia, hypotension, and oliguria due to the risk of thrombosis and AKI (grade X, strong recommendation). 


\section{Albumin infusions}

- We suggest treating patients with refractory edema (pericardial/pleural effusions, anasarca, genital edema) and/or symptomatic hypovolemia or with prerenal crisis (oliguria due to intravascular volume depletion) with human albumin infusions (grade $\mathrm{C}$, moderate recommendation).

- We suggest a starting dose of 20-25\% albumin of 0.5$1 \mathrm{~g} / \mathrm{kg}$ body weight given intravenously over a period of 4-8 $\mathrm{h}$, and adding furosemide $(1-2 \mathrm{mg} / \mathrm{kg}$ given i.v. $)$ in the middle and/or at the end of the infusion (grade $\mathrm{C}$, weak recommendation).

- Children receiving albumin infusions should initially be monitored with blood pressure and heart rate measurements every $30 \mathrm{~min}$, and the infusion slowed or ceased if they develop any symptoms suggestive of vascular overload (grade X, strong recommendation).

\section{Protein}

- There is insufficient evidence to recommend an increased protein intake in SRNS patients (ungraded).

\section{Evidence and rationale}

Severe edema in NS may be associated with either intravascular volume contraction ("underfilled patient") or volume expansion ("overfilled patient") [109]. Therefore, all measures should be tailored according to the degree of edema and intravascular volume status. Clinical indicators for intravascular volume depletion are peripheral vasoconstriction (prolonged capillary refill time), tachycardia, hypotension, and oliguria, in the setting of urinary sodium retention (fractional sodium excretion $(\mathrm{FeNa})<0.2 \%)$. In contrast, hypertension and a $\mathrm{FeNa}>0.2 \%$ would suggest an overfilled patient [110-112].

\section{Salt}

According to the "underfilled" and "overfilled" hypotheses edema formation in idiopathic NS is thought to be associated with salt retention and/or diminished excretion of salt [109]. Consequently, a strict dietary restriction of sodium intake < $2 \mathrm{mEq} / \mathrm{kg} /$ day $(<35 \mathrm{mg} / \mathrm{kg} /$ day $)$ was proposed for children with NS [110, 113, 114]. However, such a strong sodium restriction seems not to be feasible in children and may not be required in many patients. Therefore, instead of an upper limit, we recommend avoiding excessive salt intake depending on the degree of edema (Supplementary Table S11). This usually requires dietary advice - from a dietician.

\section{Fluid}

General restriction of fluids to two-thirds of maintenance have been suggested in children with NS [7111]. However, this may put patients, who already have intravascular volume depletion ("underfilled patient") despite the presence of concomitant edema, at risk for symptomatic hypovolemia. Therefore, we do not recommend routine fluid restriction in SRNS patients. Instead, we suggest a balanced fluid intake taking into account urine output, volume status, and serum sodium (low serum sodium suggests fluid overload). Patients should avoid salty foods, as they increase thirst (Supplementary Table S11).

\section{Diuretics}

Treatment of severe edema in children with NS with diuretics alone is safe and effective in the presence of volume expansion ("overfilled patient") [113], whereas aggressive treatment with diuretics carries the risk of intravascular hypovolemia, AKI, and thrombosis in "underfilled patients" [115]. Therefore, we suggest considering treatment with diuretics (preferably loop diuretics) in patients with severe edema only when intravascular volume depletion has been excluded based on the abovementioned clinical indicators. Combination therapy with metolazone, thiazides, or potassium sparing diuretics including the epithelial sodium channel blocker amiloride and the aldosterone antagonist spironolactone can enhance diuresis as compared with a loop diuretic alone and should be considered in patients with refractory edema [116]. However, patients need to be carefully monitored to avoid severe hypokalemia or hyperkalemia, volume depletion and alkalosis [117-120]. Since furosemide has a short duration of action $\left(t_{1 / 2} 6 \mathrm{~h}\right)$ and great variation in oral bioavailability (10-100\%), it should be administered at least twice daily as oral doses or intravenously if the diuretic response is poor $[121,122]$.

\section{Albumin infusions}

Albumin infusions in combination with loop diuretics increase diuresis via improved oncotic pressure and renal hemodynamics in patients with severe refractory edema, especially when used in "underfilled patients" [123-125]. However, they work only transiently [126], and are associated with allergic reactions [127], respiratory failure, and congestive heart failure, especially when given too rapidly, used in "overfilled patients," and patients with oliguria [126]. Therefore, careful assessment of the patient's intravascular volume status and urine output is mandatory [110]. Dosages up to $1 \mathrm{~g} / \mathrm{kg}$ given as 20-25\% albumin over a period of at least $4 \mathrm{~h}$ are thought to be safe [128]. We suggest restricting albumin infusions to patients with severe edema (pericardial/ pleural effusions, anasarca, genital edema), symptomatic hypovolemia, or with prerenal crisis. Adding furosemide in the middle and/or at the end of the infusion enhances the diuretic response. 


\section{Protein intake}

Hypoalbuminemia is associated with several complications in SRNS including thrombosis and risk of AKI [115], but there is no evidence that increased oral protein intake improves serum albumin levels or patient outcome [129].

\section{Recommendations for lifestyle}

- We recommend supporting physical activity and a healthy nutrition in children with SRNS and adapting to the patient's ability and stage of CKD. We recommend advising against smoking (grade $\mathrm{C}$, moderate recommendation)

\section{Evidence and rationale}

Patients with SRNS have an increased risk for cardiovascular disease [130] and impaired bone health [131, 132]. Therefore, regular physical activity; refraining from smoking, vaping, or substance use; and a healthy nutrition as in the general population are recommended. Nutrition should be guided by a dietician allowing adequate energy intake and avoiding high salt (vide supra) or phosphorus intake and adapted to the child's age or height age in short children, and stage of CKD [133, 134]. Eating home-prepared meals using fresh ingredients instead of canned, frozen, or packaged meals are preferred (Table S11), since the latter has a much higher content of salt and inorganic phosphorus which is up to $100 \%$ absorbed by the intestine [134].

\section{Monitoring and management of complications of NS and side effects of medications}

\section{Monitoring of complications}

- We recommend monitoring for complications of the persistent NS and medication side effects (see Table 4) (grade $\mathrm{B}$, moderate recommendation).

\section{Evidence and rationale}

Disease-related complications include infections, hypogammaglobulinemia, hyperlipidemia, hypertension, hypothyroidism, venous thromboembolism, vitamin D deficiency, growth failure, obesity, malnutrition, AKI, and CKD. Potential side effects of medications are shown in Table 4, and primary outcome parameters for use in registries/studies are shown in Supplementary Table S9.
Interventions-prevention and treatment

\section{Hypogammaglobulinemia-immunoglobulin substitution}

- We suggest that immunoglobulin substitution be considered in cases of low serum IgG levels AND recurrent and/ or severe infections (grade $\mathrm{D}$, weak recommendation).

\section{Evidence and rationale}

Arguments against routine IgG substitution in patients with low IgG include (a) the rapid urinary loss following infusion, (b) commercial immunoglobulin preparations contain low IgG titers against bacteria mainly responsible for the septic episodes (staphylococci, streptococci, gram-negative bacteria) [135], and (c) the high costs. We thus suggest considering prophylactic IgG substitution as in other cases of secondary hypogammaglobulinemia in patients presenting with recurrent and/or severe infections [136].

\section{Antibiotic prophylaxis}

- We do not recommend routine antibiotic prophylaxis in children with SRNS (grade C, weak recommendation).

- We suggest antibiotic prophylaxis with cotrimoxazole in patients treated with rituximab for a period of 3 up-to 6 months depending on B cell recovery and immunosuppressive co-medication (grade C, weak recommendation).

\section{Evidence and rationale}

Although $60 \%$ of NS-associated deaths are attributable to infection [137], there is no evidence to recommend antibiotic prophylaxis in children with SRNS [138-142]. Thirty to $50 \%$ of infections were due to pneumococcal infection, with the rest are due to gram-negative bacilli principally E. coli $[2,114,137,143-146]$. It was estimated that 110 children would need to be treated for 1 year to prevent 1 pneumococcal peritonitis [147]. Given the high mortality of Pneumocystis jirovecii pneumonia, we suggest to administer cotrimoxazole in patients on rituximab therapy for a period of 3 up to 6 months depending on $\mathrm{B}$ cell recovery and use of additional immunosuppressive comedications [75]. Prophylactic cotrimoxazole dosing is recommend with $5-10 \mathrm{mg} \mathrm{TMP} / \mathrm{kg} /$ day or $150 \mathrm{mg} \mathrm{TMP} /$ $\mathrm{m}^{2} /$ day in infants (at least 4 weeks of age) and children, given as single daily dose or in two divided doses every $12 \mathrm{~h} 3$ times weekly (on consecutive or alternate days) with 
a maximum TMP dose of $320 \mathrm{mg} /$ day [148]. The oral dosing in adolescents is 80 to $160 \mathrm{mg}$ TMP daily or $160 \mathrm{mg}$ TMP 3 times per week [149]. Whereas a 50\% dose reduction of cotrimoxazole is required when eGFR $<30 \mathrm{ml} / \mathrm{m}^{2} /$ min, use of cotrimoxazole is not recommend with eGFR $<$ $15 \mathrm{ml} / \mathrm{m}^{2} / \mathrm{min}$. In those cases, an alternative option may be prophylactic aerosolized pentamidin, but there is insufficient evidence in the efficacy.

\section{Vaccination}

- We recommend reviewing the child's vaccination status at disease onset and completing all vaccinations without delay, especially for encapsulated bacteria (pneumococcal, meningococcal, Haemophilus influenzae) and, if possible, varicella-zoster virus (grade $\mathrm{A}$, strong recommendation).

- We suggest administering inactivated influenza vaccine annually (grade A, strong recommendation).

- We recommend following national vaccination guidelines for the administration of inactive and live attenuated vaccines in immunocompromised patients (grade A, strong recommendation)

- Live vaccines should not be given in SRNS patients on daily immunosuppressive medication including CNIs, MMF, and PDN (grade X, strong recommendation).

\section{Prevention of varicella infection}

- We recommend treating susceptible patients (i.e., those not or inadequately immunized to varicella and exposed to chickenpox) with varicella-zoster immunoglobulin (VZIG) (grade A, strong recommendation).

- If VZIG is not available, we suggest treatment with oral acyclovir (10 mg/kg QID for 7 days) within 7-10 days of exposure (grade $\mathrm{C}$, moderate recommendation).

- We recommend varicella vaccine should be administered to unimmunized patients in remission and not on immunosuppressive medications (grade A, strong recommendation).

\section{Evidence and rationale}

Varicella infection can be life threatening in children with SRNS. The Food and Drug Administration (FDA) approved VZIG for reducing chickenpox symptoms in susceptible patients, i.e., those not immunized and having no history of chickenpox [150]. VZIG should be given as soon as possible up to 10 days post-exposure [151-154]. Unfortunately, VZIG is not readily available in most countries. Two small studies in 52 immuno-competent children and one in 8 children with renal disease on corticosteroids suggest that administration of acyclovir reduces the risk of chickenpox when given within 7-10 days after exposure and continued for 7 days [155-157]. Once in remission and not on immunosuppressive medications, varicella vaccine should be administered in unimmunized patients and family members.

\section{Prevention of thrombosis}

- We recommend mobilizing patients as much as possible and not placing central venous lines, except for a specific and transient need (grade $\mathrm{X}$, strong recommendation).

- There is insufficient evidence to recommend routine prophylactic anticoagulation for children with SRNS and with no prior history or risk of thrombosis (ungraded).

- We suggest preventive anticoagulation with low molecular weight heparin or oral anticoagulants in those patients with a previous history of venous thromboembolic events, and consideration of treatment for those with additional risk factors (indwelling central venous lines, known hereditary thrombophilic predisposition, acute illnesses with hospitalization, infection or risk of dehydration) (grade C, weak recommendation).

- We suggest thrombophilic screening in SRNS patients with additional risk factors including central venous lines, persistent nephrotic range proteinuria, and positive family history for thrombophilic predisposition (Table 2) (grade $\mathrm{C}$, weak recommendation).

\section{Evidence and rationale}

A $3 \%$ incidence of thromboembolic events has been reported in children with NS (summarized in [158-160]. Risk factors include disease-related hypercoagulability, underlying thrombophilic predisposition, infections [161], and treatment, e.g., central venous lines. In all SRNS children, baseline coagulation tests (stated in Table 2) should be performed during the initial workup. We suggest extending the thrombophilic screening in patients with high-risk (previous thrombotic events or known hereditary thrombotic predisposition) by screening for hereditary deficiencies of anticoagulant proteins (e.g., protein $\mathrm{C}$, protein $\mathrm{S}$, and antithrombin) and singlenucleotide polymorphisms in the prothrombin (factor II G20210A) and factor V genes (factor V G1691A). We also suggest considering preventive anticoagulation with low-molecular weight heparin in SRNS patients at high thrombotic risk for the short term, with vitamin $\mathrm{K}$ antagonists for the long term [158]. 


\section{Treatment of hyper- or dyslipidemia}

- We suggest considering age-dependent lipid-lowering treatment in children with persistent multidrug-resistant NS and persistently high fasting LDL-cholesterol (> $130 \mathrm{mg} / \mathrm{dl}$; > $3.4 \mathrm{mmol} / \mathrm{l})($ grade $\mathrm{C}$, weak recommendation).

\section{Evidence and rationale}

Prolonged hyper-/dyslipidemia complicates persistent NS and is a risk factor for cardiovascular morbidity, but data to guide antihyperlipidemic treatment in children are scarce [162-166]. Uncontrolled studies in children with NS showed a reduction in LDL and total cholesterol levels by $30-40 \%$ using a combination of statins and lifestyle changes, but a RCT in children with SRNS showed no significant reduction in lipid levels [167-169]. Given the high cardiovascular morbidity associated with dyslipidemia, we suggest considering lipid-lowering treatment in children with SRNS and persistent LDLcholesterol levels $>130 \mathrm{mg} / \mathrm{dl}(3.4 \mathrm{mmol} / \mathrm{l})$, starting with lifestyle changes, including dietary modifications, enhanced physical activity and weight control [166]. There is no evidence to recommend the use of lipid-lowering statins in NS. Some experts suggest considering statins when fasting LDLcholesterol is persistently $>160 \mathrm{mg} / \mathrm{dl}(4.1 \mathrm{mmol} / \mathrm{l})[140,170]$ or earlier $(>130 \mathrm{mg} / \mathrm{dl}(3.4 \mathrm{mmol} / \mathrm{l}))$, in case of additional cardiovascular risk factors [166].

\section{Calcium, magnesium, and vitamin D supplementations}

- We suggest administering oral calcium if hypocalcemia exists based on ionized and/or albumin-corrected calcium levels (grade $\mathrm{C}$, weak recommendation).

- We suggest supplementing with cholecalciferol or ergocalciferol if 25-OH-vitamin D levels are low $(<30$ $\mathrm{ng} / \mathrm{mL}$ ) (grade $\mathrm{C}$, moderate recommendation).

- We suggest administering oral magnesium in case of symptomatic hypomagnesemia (grade D, weak recommendation).

\section{Evidence and rationale}

Children with SRNS have urinary losses of vitamin-D binding protein and 25-dihydroxyvitamin D and may develop vitamin $\mathrm{D}$ deficiency leading to hypocalcemia, hyperparathyroidism, and impaired bone mineralization [171]. Vitamin D supplementation in these patients is effective [172-174], and recommended as in other CKD patients [175]. CNI treatment may cause hypomagnesemia causing leg cramps. Administering oral magnesium will avoid symptomatic hypomagnesemic episodes.

\section{Thyroid hormone replacement}

- We recommend substituting levothyroxine (T4) in case of hypothyroidism (grade A, strong recommendation).

\section{Evidence and rationale}

Hypothyroidism in children with SRNS is a result of urinary loss of thyroxine-binding proteins [176, 177]. Therefore, TSH and free T4 levels should be regularly monitored in patients with persistently high-grade proteinuria (Table 2) [178, 179]. For those children with TSH levels $>10 \mathrm{mU} / 1$ and low free T4, we recommend treating with levothyroxine (T4) [180]. In asymptomatic children with TSH elevations of 4.5-10 mU/1 and normal free T4, thyroid function can be monitored periodically and the indication for treatment re-evaluated $[177,180,181]$.

\section{Treatment of hypertension and CKD-associated complications}

- We recommend treatment of hypertension and CKDassociated complications such as anemia, metabolic acidosis, and hyperparathyroidism, according to current guidelines (grade $\mathrm{A}$, strong recommendation).

\section{Evidence and rationale}

Children with SRNS have a significantly increased risk for cardiovascular disease $[130,132]$. As in any child with CKD, high blood pressure ( $>95$ th age-sex and height specific percentile) should be treated aiming for blood pressure values $<75$ th percentile in children without proteinuria, and $<50$ th percentile in children with proteinuria $[182,183]$. Other CKDassociated complications should be treated according to current guidelines [133, 175, 184].

\section{Diagnosis, prevention, and treatment of relapsing SRNS in native kidneys}

\section{Prevention of relapse}

- No clinical or histological parameters at initial clinical presentation are available to predict relapsing SRNS (ungraded). 


\section{Evidence and rationale}

It is unknown to what degree medications should be tapered or discontinued once remission is achieved [53, 71]. Relapse occurred in up to $70 \%$ of those responding to CNI therapy after discontinuation at 6 or 12 months. We recommend continuing immunosuppressive therapy with CNI or MMF after remission over a period of at least 1 year $[6,57]$. Gradual reduction of CNI/MMF instead of abrupt stopping may prevent an early relapse [50].

\section{Treatment of relapse}

\section{Relapse on CNI treatment}

- We recommend adherence to CNIs be monitored using serum trough levels according to the monitoring schedule shown in Table 2 (grade C, moderate recommendation)

- We suggest administering oral PDN $60 \mathrm{mg} / \mathrm{m}^{2}$ daily until remission is achieved or for a maximum period of 4 weeks, with subsequent taper when remission is achieved (grade $\mathrm{C}$, weak recommendation).

- In case of no response, frequent relapses, or side effects of medications, we recommend following the refractory SRNS protocol (see "Second-line approaches") (ungraded).

\section{Relapse post withdrawal of immunosuppressive treatment}

- We suggest giving oral PDN (60 mg/ $\mathrm{m}^{2}$ daily) until remission is achieved or for a maximum period of 4 weeks, with subsequent taper when remission is achieved. Alternatively, we suggest restarting the immunosuppressive agent, which was able to prevent, relapses (grade D, weak recommendation).

- In cases of no complete response within 4 weeks, frequent relapses or side effects of medications, we recommend following the refractory SRNS protocol (see "Second-line approaches") (ungraded).

\section{Evidence and rationale}

\section{Relapsing SRNS and role of steroids}

Several studies have shown the effectiveness of PDN in relapsing SRNS at $2 \mathrm{mg} / \mathrm{kg} /$ day to induce remission [52, 53] with a change to QOD PDN, followed by tapering until the end of month $6[185,186]$. Intravenous MPDN was also effective in inducing remission in relapsing patients [71, 74, 187]. Re-starting non-glucocorticoid medications which were effective in the particular patient is also reasonable.

\section{Management of children with ESKD}

\section{Dialyzed patients}

- We recommend that urine protein excretion should be measured prior to transplantation in patients with residual native kidney function to facilitate accurate posttransplant surveillance for recurrence (grade A, strong recommendation).

- We recommend that the anticipated recurrence risk after renal transplantation should be discussed with the family in renal replacement therapy planning (grade A, strong recommendation).

- If transplant will occur before resolution of NS in the setting of ESKD, we suggest considering medical or surgical nephrectomies prior to transplantation (grade D, weak recommendation).

\section{Evidence and rationale}

Preparation for transplantation ideally requires the resolution of NS to minimize the risk for venous thromboembolism and improve the accuracy of monitoring for posttransplant recurrence. If adequate resolution of proteinuria does not occur after the initiation of dialysis based on 24-h urine protein, we suggest considering medical or surgical nephrectomies. However, the benefits of residual kidney function and urine output in facilitating dialysis should also be considered.

\section{Selection of transplant recipients}

- We recommend that genetic testing be performed before transplantation to inform SRNS recurrence risk (grade B, moderate recommendation).

- We recommend kidney transplant be offered to children with ESKD secondary to SRNS regardless of genetic or non-genetic cause of SRNS (grade B, moderate recommendation).

- We suggest that the risks and benefits of a repeat transplant in a patient with a history of SRNS recurrence should be discussed within the transplant team and with the patient and family in planning for a repeat-transplant (grade $\mathrm{A}$, strong recommendation). 


\section{Evidence and rationale}

Factors associated with post-transplant recurrence of SRNS are non-genetic vs. monogenic forms of SRNS (recurrence $24 \%$ vs. $0 \%$ in Brazilian cohort [188] and $50 \%$ vs. $7 \%$ in European cohort [101]; initial steroid resistance vs. sensitivity (OR 30, 95\% CI 6.6-135.9) [189]; time to ESKD < 48 vs. > 48 months (OR 11.7, 95\% CI 1.53-89.1) and glomerulosclerosis percentage $<55 \%$ at renal biopsy (OR 16, 95\% CI 1.45-1.76) [190]. Children with a history of SRNS recurrence in a prior transplant have a $>80 \%$ likelihood of recurrence in a subsequent transplant [188]. Complete and partial remission has been reported in $63 \%$ and $8 \%$ of patients with recurrent NS post-transplant with a 10 years allograft survival of $50 \%$ [191, 192].

\section{Selection of transplant donors}

- We recommend candidate living-related allograft donors undergo genetic testing as part of evaluation in the setting of genetic SRNS if available (grade X, strong recommendation).

- We recommend a donor candidate with a pathogenic or likely pathogenic variant in a dominant gene, with or without symptoms, be excluded as a potential donor (grade X, strong recommendation).

- A heterozygous carrier of a recessive SRNS genetic variant may be considered a potential donor, after genetic counseling (except for carriers of pathological variations in COL4A5, COL4A3, and COL4A4) (grade C, weak recommendation).

- An asymptomatic carrier of a variant of unknown significance may be considered as a transplant donor following extensive evaluation and counseling where other organ donation options are not available (grade C, weak recommendation).

- We recommend that the expected risk of recurrence and premature allograft failure be included in the consideration of donor candidacy (grade A, strong recommendation).

\section{Evidence and rationale}

Living-related kidney donation in the context of genetic kidney diseases should follow detailed donor evaluation, careful review of pattern of disease inheritance, and genetic counseling and testing $[193,194]$. While a family history of a genetic kidney disease with an autosomal recessive (AR) mode of inheritance is not considered a contraindication for living kidney donation, long-term follow-up data are lacking [193]. In cases where SRNS follows an autosomal dominant (AD) mode of inheritance, donation from living related donors from the side of family with affected members is discouraged. If it remains uncertain whether the donor candidate has a genetic kidney disease and whether the disease can cause CKD, donation should proceed only after informing the donor candidate of the risks of donation if the disease manifests later in life [193, 194].

Hemizygous carriers (mothers and sisters) of COL $4 A 5$ defects should be dissuaded from kidney donation, since they are known to develop ESKD [195]. Similar advice should be given to donors with pathogenic heterozygous defects in other COL4A (COL4A3 and COL4A4). Further, the risk to donors carrying heterozygous NPHS2 mutations may be modified by variants such as $\mathrm{R} 229 \mathrm{Q}$, which are considered to have a dominant-negative variant that might theoretically pose risk to the donor [196, 197]. Tests including evaluation of proteinuria and hematuria done as part of the donor assessment should be interpreted with special consideration in the setting of familial SRNS. If genetic evaluation of the potential donor is normal but the family history is positive, donation should proceed only after a full informed consent.

\section{Accepting living donor for kidney transplantation in view of risk of recurrence}

- Either living related or deceased donors are encouraged for patients with non-genetic SRNS receiving their first allograft (grade B, moderate recommendation).

\section{Evidence and rationale}

Similar proportions of patients with recurrence were observed among living versus deceased allografts (10-50\% vs. 3-45\%), but allograft survival was superior in living donor allografts with recurrent FSGS compared with deceased donor allografts [198-200].

Withholding transplantation from patients who have previously recurred

- We recommend, discouraging living related donation for recipients who have had disease recurrence in the first transplant (grade B, moderate recommendation).

- Deceased donor transplant may be offered to potential recipients with a history of prior allograft loss to recurrence of NS, particularly if dialysis is difficult to sustain, or associated with life-threatening events, serious infections, poor growth, and/or low quality of life (grade C, weak recommendation). 


\section{Evidence and rationale}

Transplantation should not be delayed in SRNS patients, since this does not reduce the recurrence risk [200-204]. Recurrence in first allograft indicates a $60-80 \%$ risk of recurrence in subsequent allografts [199, 203, 204]. Strategies used to manage recurrent disease (high-dose CNI, intravenous MPDN, rituximab; and extracorporeal therapies) induced remission in $\sim 60 \%$ of cases $[200,205,206]$. While a few reports suggest that early diagnosis and aggressive therapy of recurrent disease may result in outcomes comparable to those in allografts without recurrence [207, 208], outcomes after recurrence are usually poor for patients who do not respond to interventions [209-214]. Therefore, repeat transplants from living donors are discouraged in the setting of prior SRNS disease recurrence and deceased donor transplantation, rather than dialysis, is considered ethically appropriate.

\section{Prevention of recurrence after renal transplantation}

- There is insufficient evidence to recommend intervention strategies for the prevention of recurrence in children undergoing a first kidney transplant (ungraded).

- We suggest prophylactic plasmapheresis or immunoadsorption or lipid apheresis and perioperative rituximab for use in children with a history of allograft loss due to NS recurrence in a prior transplant (grade C, weak recommendation).

\section{Evidence and rationale}

There are no proven preventative strategies to reduce the likelihood of recurrence in SRNS patients undergoing the first renal transplantation. Preventative strategies for SRNS recurrence in primary, non-genetic SRNS with a history of SRNS recurrence within 1 year of transplant were shown to be effective in case reports and small series including 8 patients. They include prophylactic plasmapheresis three times weekly for 2 weeks, beginning 1 week prior to living donor transplant or within 1 day of deceased donor transplant with 1.5 plasma volume exchanges and rituximab peri-operatively or immediately after transplant with/or without a second dose posttransplant day 7 [93, 215-217].

\section{Transplant recurrence (as defined in Table 1)}

- We recommend surveillance for recurrence beginning on the day of kidney transplantation by monitoring UPCR, continued daily throughout the initial transplant hospitalization, and then continued periodically (e.g., weekly for
4 weeks, monthly for 1 year, then quarterly thereafter) (grade $\mathrm{C}$, moderate recommendation).

- We suggest in a previously anuric patient, post-transplant UPCR $\geq 100 \mathrm{mg} / \mathrm{mmol}(1 \mathrm{mg} / \mathrm{mg})$ may be indicative of early recurrence, infection, or other diagnoses and requires evaluation (grade $\mathrm{C}$, weak recommendation).

- We suggest in a patient with prevalent proteinuria at the time of transplant, an increase of UPCR $\geq 100 \mathrm{mg} / \mathrm{mmol}$ $(1 \mathrm{mg} / \mathrm{mg}$ ) may be indicative of early recurrence, infection or other diagnoses and requires evaluation (grade $\mathrm{C}$, weak recommendation).

- We suggest that early onset acute tubular necrosis (ATN) or graft non-function/dysfunction should be regarded as first signs of recurrence (grade $\mathrm{C}$, weak recommendation).

- We suggest that an allograft biopsy is not required to diagnose rapid recurrence of NS as defined in Table 1, but allograft biopsy is recommended for the exclusion of differential diagnosis in the setting of subnephrotic proteinuria, recurrence after $48 \mathrm{~h}$, or in the setting of delayed graft function (grade B, moderate recommendation).

- We suggest that a diagnostic evaluation precede adjustments of immunosuppression therapy in the setting of late NS recurrence $(\geq 3$ months post-transplant) including assessment of infection, donor-specific antibodies serologies, and histopathology including electron microscopy (grade B, moderate recommendation).

\section{Evidence and rationale}

Nephrotic syndrome may recur as early as within $24 \mathrm{~h}$ after transplantation and is indicated by a UPCR ratio $\geq 100 \mathrm{mg} /$ mmol $(1 \mathrm{mg} / \mathrm{mg})$ in a previously anuric patient (Table 1$)$. Early onset acute tubular necrosis (ATN) or graft non-function/dysfunction should be considered as a first sign of transplant recurrence $[218,219]$. A diagnosis of FSGS recurrence can be inferred on renal biopsy with diffuse foot process effacement in the absence of other histopathological findings, even if the glomerular scar defining FSGS is not present. Late-onset or insidious proteinuria requires a renal biopsy for the exclusion of the differential diagnoses including de novo TMA and antibody-mediated rejection with transplant glomerulopathy, since both can show secondary FSGS [191, 220-222].

\section{Treatment of recurrence}

- We recommend implementing NS recurrence-specific therapy as soon as possible after diagnosis is established (grade $\mathrm{X}$, strong recommendation).

- We suggest applying increasing doses of CNI, intravenous MPDN pulses, and/or plasmapheresis (or 
immunoadsorption) with or without rituximab (grade C, weak recommendation).

- We suggest initiating RAASi when no complete remission is achieved following recurrence targeted therapy (grade $\mathrm{C}$, weak recommendation).

\section{Evidence and rationale}

Strategies used to manage recurrent disease including high-dose CNI, intravenous MPDN, rituximab, and extracorporeal blood purification induced remission in $\sim 60 \%$ of transplant recurrence $[198,223]$. We suggest in patients, treated with rituximab, to administer a second dose of rituximab $\left(375 \mathrm{mg} / \mathrm{m}^{2}\right)$ in the setting of incomplete B cell depletion and/or recurrence of proteinuria.

Acknowledgments The authors acknowledge the valuable contributions of the members of the voting panel representing the IPNA regional societies, i.e., ESPN: Elena Levtchenko (Department of Pediatrics, University of Leuven, Belgium), Jun Oh (Pediatric Nephrology Department, University Children's Hospital, Hamburg, Germany), Rezan Topaloglu (Division of Pediatric Nephrology, Department of Pediatrics, School of Medicine, Hacettepe University, Ankara, Turkey), Georges Deschenes (APHP Robert-Debré, Paris, France), Pierre Cochat (Lyon, France); ANZPNA: Siah Kim (Sydney Children's Hospital Network, Sydney, Australia), Anna Francis (Queensland Children's Hospital, Brisbane, Australia), Nick Larkins (Perth Children's Hospital, Perth, Australia); JSPN: Yutaka Harita (Department of Pediatrics, University of Tokyo, Japan), Riku Hamada (Tokyo Metropolitan Children's Medical Center, Tokyo, Japan), Hiroshi Kaito (Hyogo Prefectural Kobe Children's Hospital, Kobe, Japan); ASPN: Chia-Shi Wang (Emory University and Children's Healthcare of Atlanta, Atlanta, USA), Rasheed Gbadegesin (Duke University Medical, Durham, USA), Michelle Rheault (Department of Pediatrics, University of Minnesota Medical School, Minneapolis, USA); ALANEPE: Vera Koch (Instituto da Criança HCFMUSP, Sao Paulo, Brazil), Jaime Restrepo (Fundacion Valle del Lili, Cali, Columbia), Melvin Bonilla-Felix (University of Puerto Rico-Medical School, San Juan, Puerto Rico); AFPNA: Bashir Admani (University of Nairobi, Nairobi, Kenya), Pepe Ekulu (University Hospital of Kinshasa, Kinshasa, DR Congo), Mignon McCulloch (Red Cross Children's Hospital, Cape Town, South Africa); AsPNA: Arvind Bagga (Division of Nephrology, Department of Pediatrics, All India Institute of Medical Sciences, New Delhi, India), Shen Qian (Children's Hospital of Fudan University, Shanghai, China), and Khalid Alhasan (King Saud University, Pediatric Department, Riadh, Saudi Arabia). The authors would also like to thank patient representatives acting as external experts: Chandana Guha (Research Assistant and Patient Partner, Centre for Kidney Research, The Children's Hospital at Westmead, Sydney School of Public Health, The University of Sydney, Australia); Clemens Brauner (Patient Organization for Children with CKD in Lower Saxony, Hannover, Germany); Wendy Cook (director and fundraising coordinator of patient organization "Nephrotic syndrome Trust" (NeST), UK. The authors would also like to thank Stefanie Steinmann (nutrition therapist, Children's Hospital, Hannover Medical School, Germany) for acting as an external expert and discussing this manuscript in the German Nutrition in Children with Renal Disease Working Group.
Funding information Open Access funding provided by Projekt DEAL. The International Pediatric Nephrology Association launched, organized, and funded this initiative, which included travel and accommodation costs for the core group members. The funder had no influence on the content of the guideline.

\section{Compliance with ethical standards}

Competing interests D.H. has received research grants from Kyowa Kirin and Amgen, and has received speaker and/or consultant fees from Amgen, Sandoz, Kyowa Kirin, Pfizer, Merck Serono, Horizon, and Chiesi. O.B. has received speaker and/or consultant fees from Amgen, Chiesi, Novartis, and Octapharma. These were all unrelated to the topic of this guideline. The other authors declare no competing interests.

Open Access This article is licensed under a Creative Commons Attribution 4.0 International License, which permits use, sharing, adaptation, distribution and reproduction in any medium or format, as long as you give appropriate credit to the original author(s) and the source, provide a link to the Creative Commons licence, and indicate if changes were made. The images or other third party material in this article are included in the article's Creative Commons licence, unless indicated otherwise in a credit line to the material. If material is not included in the article's Creative Commons licence and your intended use is not permitted by statutory regulation or exceeds the permitted use, you will need to obtain permission directly from the copyright holder. To view a copy of this licence, visit http://creativecommons.org/licenses/by/4.0/.

\section{References}

1. Noone DG, Iijima K, Parekh R (2018) Idiopathic nephrotic syndrome in children. Lancet 392(10141):61-74. https://doi.org/10. 1016/s0140-6736(18)30536-1

2. Eddy AA, Symons JM (2003) Nephrotic syndrome in childhood. Lancet 362(9384):629-639. https://doi.org/10.1016/s01406736(03)14184-0

3. McKinney PA, Feltbower RG, Brocklebank JT, Fitzpatrick MM (2001) Time trends and ethnic patterns of childhood nephrotic syndrome in Yorkshire, UK. Pediat Nephrol (Berlin, Germany) 16(12):1040-1044. https://doi.org/10.1007/s004670100021

4. El Bakkali L, Rodrigues Pereira R, Kuik DJ, Ket JC, van Wijk JA (2011) Nephrotic syndrome in the Netherlands: a populationbased cohort study and a review of the literature. Pediat Nephrol (Berlin, Germany) 26(8):1241-1246. https://doi.org/10.1007/ s00467-011-1851-8

5. Dossier C, Lapidus N, Bayer F, Sellier-Leclerc AL, Boyer O, de Pontual L, May A, Nathanson S, Orzechowski C, Simon T, Carrat F, Deschenes G (2016) Epidemiology of idiopathic nephrotic syndrome in children: endemic or epidemic? Pediat Nephrol (Berlin, Germany) 31(12):2299-2308. https://doi.org/10.1007/s00467016-3509-z

6. Lombel RM, Gipson DS, Hodson EM (2013) Treatment of steroid-sensitive nephrotic syndrome: new guidelines from KDIGO. Pediat Nephrol (Berlin, Germany) 28(3):415-426. https://doi.org/10.1007/s00467-012-2310-x

7. Tullus K, Webb H, Bagga A (2018) Management of steroidresistant nephrotic syndrome in children and adolescents. Lancet Child Adolesc Health 2(12):880-890. https://doi.org/10.1016/ s2352-4642(18)30283-9 
8. Bierzynska A, McCarthy HJ, Soderquest K, Sen ES, Colby E, Ding WY, Nabhan MM, Kerecuk L, Hegde S, Hughes D, Marks S, Feather S, Jones C, Webb NJ, Ognjanovic M, Christian M, Gilbert RD, Sinha MD, Lord GM, Simpson M, Koziell AB, Welsh GI, Saleem MA (2017) Genomic and clinical profiling of a national nephrotic syndrome cohort advocates a precision medicine approach to disease management. Kidney Int 91(4):937947. https://doi.org/10.1016/j.kint.2016.10.013

9. El-Reshaid K, El-Reshaid W, Madda J (2005) Combination of immunosuppressive agents in treatment of steroid-resistant minimal change disease and primary focal segmental glomerulosclerosis. Ren Fail 27(5):523-530. https://doi.org/10. 1080/08860220500198623

10. Sampson MG (2017) The democratization of genomic inquiry empowers our understanding of nephrotic syndrome. Transplantation 101(12):2814-2815. https://doi.org/10.1097/tp. 0000000000001897

11. Trautmann A, Schnaidt S, Lipska-Zietkiewicz BS, Bodria M, Ozaltin F, Emma F, Anarat A, Melk A, Azocar M, Oh J, Saeed B, Gheisari A, Caliskan S, Gellermann J, Higuita LMS, Jankauskiene A, Drozdz D, Mir S, Balat A, Szczepanska M, Paripovic D, Zurowska A, Bogdanovic R, Yilmaz A, Ranchin B, Baskin E, Erdogan O, Remuzzi G, Firszt-Adamczyk A, KuzmaMroczkowska E, Litwin M, Murer L, Tkaczyk M, Jardim H, Wasilewska A, Printza N, Fidan K, Simkova E, Borzecka H, Staude H, Hees K, Schaefer F (2017) Long-term outcome of steroid-resistant nephrotic syndrome in children. J Am Soc Nephrol 28(10):3055-3065. https://doi.org/10.1681/asn. 2016101121

12. Chen Y, Yang K, Marusic A, Qaseem A, Meerpohl JJ, Flottorp S, Akl EA, Schunemann HJ, Chan ES, Falck-Ytter Y, Ahmed F, Barber S, Chen C, Zhang M, Xu B, Tian J, Song F, Shang H, Tang K, Wang Q, Norris SL (2017) A reporting tool for practice guidelines in health care: the RIGHT statement. Ann Intern Med 166(2):128-132. https://doi.org/10.7326/m16-1565

13. Guyatt GH, Oxman AD, Kunz R, Atkins D, Brozek J, Vist G, Alderson P, Glasziou P, Falck-Ytter Y, Schunemann HJ (2011) GRADE guidelines: 2. Framing the question and deciding on important outcomes. J Clin Epidemiol 64(4):395-400. https://doi. org/10.1016/j.jclinepi.2010.09.012

14. Liu ID, Willis NS, Craig JC, Hodson EM (2019) Interventions for idiopathic steroid-resistant nephrotic syndrome in children. Cochrane Database System Rev 2019(11). https://doi.org/10. 1002/14651858.CD003594.pub6

15. Drube J, Wan M, Bonthuis M, Wuhl E, Bacchetta J, Santos F, Grenda R, Edefonti A, Harambat J, Shroff R, Tonshoff B, Haffner D (2019) Clinical practice recommendations for growth hormone treatment in children with chronic kidney disease. 15(9): 577-589. doi:https://doi.org/10.1038/s41581-019-0161-4

16. Classifying recommendations for clinical practice guidelines (2004). Pediatrics 114 (3):874-877. doi:https://doi.org/10.1542/ peds.2004-1260

17. The primary nephrotic syndrome in children. Identification of patients with minimal change nephrotic syndrome from initial response to prednisone. A report of the International Study of Kidney Disease in Children (1981). J Pediatr 98 (4):561-564. doi:https://doi.org/10.1016/s0022-3476(81)80760-3

18. Slev PR, Bunker AM, Owen WE, Roberts WL (2010) Pediatric reference intervals for random urine calcium, phosphorus and total protein. Pediatr Nephrol (Berlin, Germany) 25(9):1707-1710. https://doi.org/10.1007/s00467-010-1544-8

19. Hogg RJ, Portman RJ, Milliner D, Lemley KV, Eddy A, Ingelfinger $J$ (2000) Evaluation and management of proteinuria and nephrotic syndrome in children: recommendations from a pediatric nephrology panel established at the National Kidney Foundation conference on proteinuria, albuminuria, risk, assessment, detection, and elimination (PARADE). Pediatrics 105(6): 1242-1249. https://doi.org/10.1542/peds.105.6.1242

20. de Onis M, Habicht JP (1996) Anthropometric reference data for international use: recommendations from a World Health Organization Expert Committee. Am J Clin Nutr 64(4):650-658. https://doi.org/10.1093/ajcn/64.4.650

21. Bjork J, Nyman U (2019) Validation of standardized creatinine and cystatin C GFR estimating equations in a large multicentre European cohort of children 34 6):1087-1098. doi:https://doi.org/ 10.1007/s00467-018-4185-y

22. Gellermann J, Weber L, Pape L, Tonshoff B, Hoyer P, Querfeld U (2013) Mycophenolate mofetil versus cyclosporin A in children with frequently relapsing nephrotic syndrome. J Am Soc Nephrol 24(10):1689-1697. https://doi.org/10.1681/asn.2012121200

23. Lovric S, Ashraf S, Tan W, Hildebrandt F (2016) Genetic testing in steroid-resistant nephrotic syndrome: when and how? Nephrol Dial Transplant 31(11):1802-1813. https://doi.org/10.1093/ndt/ gfv355

24. Preston R, Stuart HM, Lennon R (2019) Genetic testing in steroidresistant nephrotic syndrome: why, who, when and how? Pediat Nephrol (Berlin, Germany) 34(2):195-210. https://doi.org/10. 1007/s00467-017-3838-6

25. Emma F, Salviati L (2017) Mitochondrial cytopathies and the kidney. Nephrol Therapeut 13(Suppl 1):S23-s28. https://doi.org/ 10.1016/j.nephro.2017.01.014

26. Trautmann A, Lipska-Zietkiewicz BS, Schaefer F (2018) Exploring the clinical and genetic spectrum of steroid resistant nephrotic syndrome: the PodoNet Registry. Front Pediatr 6:200. https://doi.org/10.3389/fped.2018.00200

27. Sen ES, Dean P, Yarram-Smith L, Bierzynska A, Woodward G, Buxton C, Dennis G, Welsh GI, Williams M, Saleem MA (2017) Clinical genetic testing using a custom-designed steroid-resistant nephrotic syndrome gene panel: analysis and recommendations. J Med Genet 54(12):795-804. https://doi.org/10.1136/jmedgenet2017-104811

28. Kitamura A, Tsukaguchi H, Iijima K, Araki J, Hattori M, Ikeda M, Honda M, Nozu K, Nakazato H, Yoshikawa N, Kagami S, Muramatsu M, Choi Y, Cheong HI, Doi T (2006) Genetics and clinical features of 15 Asian families with steroid-resistant nephrotic syndrome. Nephrol Dial Transplant 21(11):3133-3138. https://doi.org/10.1093/ndt/gfl347

29. Maruyama K, Iijima K, Ikeda M, Kitamura A, Tsukaguchi H, Yoshiya K, Hoshii S, Wada N, Uemura O, Satomura K, Honda M, Yoshikawa N (2003) NPHS2 mutations in sporadic steroidresistant nephrotic syndrome in Japanese children. Pediat Nephrol (Berlin, Germany) 18(5):412-416. https://doi.org/10.1007/ s00467-003-1120-6

30. Yu Z, Ding J, Huang J, Yao Y, Xiao H, Zhang J, Liu J, Yang J (2005) Mutations in NPHS2 in sporadic steroid-resistant nephrotic syndrome in Chinese children. Nephrol Dial Transplant 20(5): 902-908. https://doi.org/10.1093/ndt/gfh769

31. Anochie IC, Eke FU, Okpere AN (2012) Familial focal segmental glomerulosclerosis (FSGS) in a Nigerian family and exclusion of mutations in NPHS2,WT1 and APOL1. West Afr J Med 31(4): 273-276

32. Hommos MS, Zeng C, Liu Z, Troost JP, Rosenberg AZ, Palmer M, Kremers WK, Cornell LD, Fervenza FC, Barisoni L, Rule AD (2018) Global glomerulosclerosis with nephrotic syndrome; the clinical importance of age adjustment. Kidney Int 93(5):11751182. https://doi.org/10.1016/j.kint.2017.09.028 
33. Trautmann A, Bodria M, Ozaltin F, Gheisari A, Melk A, Azocar M, Anarat A, Caliskan S, Emma F, Gellermann J, Oh J, Baskin E, Ksiazek J, Remuzzi G, Erdogan O, Akman S, Dusek J, Davitaia T, Ozkaya O, Papachristou F, Firszt-Adamczyk A, Urasinski T, Testa S, Krmar RT, Hyla-Klekot L, Pasini A, Ozcakar ZB, Sallay P, Cakar N, Galanti M, Terzic J, Aoun B, Caldas Afonso A, Szymanik-Grzelak H, Lipska BS, Schnaidt S, Schaefer F (2015) Spectrum of steroid-resistant and congenital nephrotic syndrome in children: the PodoNet registry cohort. Clin J Am Soc Nephrol 10(4):592-600. https://doi.org/10.2215/cjn.06260614

34. Richards S, Aziz N, Bale S, Bick D, Das S, Gastier-Foster J, Grody WW, Hegde M, Lyon E, Spector E, Voelkerding K, Rehm HL (2015) Standards and guidelines for the interpretation of sequence variants: a joint consensus recommendation of the. Am College Med Genet Genom Assoc Molec Pathol 17(5):405424. https://doi.org/10.1038/gim.2015.30

35. Watanabe A, Feltran LS, Sampson MG (2019) Genetics of nephrotic syndrome presenting in childhood: Core Curriculum 2019. Genet Med. https://doi.org/10.1053/j.ajkd.2019.01.033

36. Weber S, Buscher AK, Hagmann H, Liebau MC, Heberle C, Ludwig M, Rath S, Alberer M, Beissert A, Zenker M, Hoyer PF, Konrad M, Klein HG, Hoefele J (2016) Dealing with the incidental finding of secondary variants by the example of SRNS patients undergoing targeted next-generation sequencing. Pediat Nephrol (Berlin, Germany) 31(1):73-81. https://doi.org/10.1007/s00467015-3167-6

37. Gbadegesin RA, Winn MP, Smoyer WE (2013) Genetic testing in nephrotic syndrome-challenges and opportunities. Pediat Nephrol (Berlin, Germany) 9(3):179-184. https://doi.org/10.1038/nrneph. 2012.286

38. Wuhl E, Trivelli A, Picca S, Litwin M, Peco-Antic A, Zurowska A, Testa S, Jankauskiene A, Emre S, Caldas-Afonso A, Anarat A, Niaudet P, Mir S, Bakkaloglu A, Enke B, Montini G, Wingen AM, Sallay P, Jeck N, Berg U, Caliskan S, Wygoda S, HohbachHohenfellner K, Dusek J, Urasinski T, Arbeiter K, Neuhaus T, Gellermann J, Drozdz D, Fischbach M, Moller K, Wigger M, Peruzzi L, Mehls O, Schaefer F (2009) Strict blood-pressure control and progression of renal failure in children. N Engl J Med 361(17):1639-1650. https://doi.org/10.1056/NEJMoa0902066

39. Bagga A, Mudigoudar BD, Hari P, Vasudev V (2004) Enalapril dosage in steroid-resistant nephrotic syndrome. Pediat Nephrol (Berlin, Germany) 19(1):45-50. https://doi.org/10.1007/s00467003-1314-y

40. van den Belt SM, Heerspink HJL, Gracchi V, de Zeeuw D, Wuhl E, Schaefer F (2018) Early proteinuria lowering by angiotensinconverting enzyme inhibition predicts renal survival in children with CKD. Pediat Nephrol (Berlin, Germany) 29(8):2225-2233. https://doi.org/10.1681/asn.2018010036

41. Xie X, Liu Y, Perkovic V, Li X, Ninomiya T, Hou W, Zhao N, Liu L, Lv J, Zhang H, Wang H (2016) Renin-angiotensin system inhibitors and kidney and cardiovascular outcomes in patients with CKD: a Bayesian network meta-analysis of randomized clinical trials. Am J Kidney Dis 67(5):728-741. https://doi.org/10.1053/j. ajkd.2015.10.011

42. Ruggenenti P, Cravedi P, Chianca A, Caruso M, Remuzzi G (2017) Achieving remission of proteinuria in childhood. CKD. 32(2):321-330. https://doi.org/10.1007/s00467-016-3495-1

43. Yi Z, Li Z, Wu XC, He QN, Dang XQ, He XJ (2006) Effect of fosinopril in children with steroid-resistant idiopathic nephrotic syndrome. Pediat Nephrol (Berlin, Germany) 21(7):967-972. https://doi.org/10.1007/s00467-006-0096-4

44. Weir MR, Lakkis JI, Jaar B, Rocco MV, Choi MJ, Kramer HJ, Ku E (2018) Use of renin-angiotensin system blockade in advanced CKD: an NKF-KDOQI controversies report. Am J Kidney Dis 72(6):873-884. https://doi.org/10.1053/j.ajkd.2018.06.010
45. Tullus K (2011) Safety concerns of angiotensin II receptor blockers in preschool children. Arch Dis Child 96(9):881-882. https://doi.org/10.1136/archdischild-2011-300172

46. Stotter BR, Ferguson MA (2019) Should ACE inhibitors and ARBs be used in combination in children? Pediat Nephrol (Berlin, Germany) 34(9):1521-1532. https://doi.org/10.1007/ s00467-018-4046-8

47. Polifka JE (2012) Is there an embryopathy associated with firsttrimester exposure to angiotensin-converting enzyme inhibitors and angiotensin receptor antagonists? A critical review of the evidence. Birth Defects Res A, Clin Molec Teratol 94(8):576-598. https://doi.org/10.1002/bdra.23027

48. Lieberman KV, Tejani A (1996) A randomized double-blind placebo-controlled trial of cyclosporine in steroid-resistant idiopathic focal segmental glomerulosclerosis in children. J Am Soc Nephrol 7(1):56-63

49. Garin EH, Orak JK, Hiott KL, Sutherland SE (1988) Cyclosporine therapy for steroid-resistant nephrotic syndrome. A controlled study. Am J Dis Children (1960) 142(9):985-988. https://doi. org/10.1001/archpedi.1988.02150090083029

50. Ponticelli C, Rizzoni G, Edefonti A, Altieri P, Rivolta E, Rinaldi S, Ghio L, Lusvarghi E, Gusmano R, Locatelli F et al (1993) A randomized trial of cyclosporine in steroid-resistant idiopathic nephrotic syndrome. Kidney Int 43(6):1377-1384. https://doi.org/ 10.1038/ki.1993.194

51. Bhaumik SKMA, Barman SK (2002) Comparison of pulse methylprednisolone vs. cyclosporine based therapy in steroid resistant focal segmental glomerulosclerosis (abstract). Indian J Nephrol 12(4): 190

52. Gipson DS, Trachtman H, Kaskel FJ, Greene TH, Radeva MK, Gassman JJ, Moxey-Mims MM, Hogg RJ, Watkins SL, Fine RN, Hogan SL, Middleton JP, Vehaskari VM, Flynn PA, Powell LM, Vento SM, McMahan JL, Siegel N, D'Agati VD, Friedman AL (2011) Clinical trial of focal segmental glomerulosclerosis in children and young adults. Kidney Int 80(8):868-878. https://doi.org/ 10.1038/ki.2011.195

53. Choudhry S, Bagga A, Hari P, Sharma S, Kalaivani M, Dinda A (2009) Efficacy and safety of tacrolimus versus cyclosporine in children with steroid-resistant nephrotic syndrome: a randomized controlled trial. Am J Kidney Dis 53(5):760-769. https://doi.org/ 10.1053/j.ajkd.2008.11.033

54. Valverde S (2010) Efficacy of prednison-tacrolimus vs. prednisone-cyclosporine in steroid-resistant nephrotic syndrome [abstract]. Pediatr Nephrol 25(9):1804

55. Gulati A, Sinha A, Gupta A, Kanitkar M, Sreenivas V, Sharma J, Mantan M, Agarwal I, Dinda AK, Hari P, Bagga A (2012) Treatment with tacrolimus and prednisolone is preferable to intravenous cyclophosphamide as the initial therapy for children with steroid-resistant nephrotic syndrome. Kidney Int 82(10):1130 1135. https://doi.org/10.1038/ki.2012.238

56. Plank C, Kalb V, Hinkes B, Hildebrandt F, Gefeller O, Rascher W (2008) Cyclosporin A is superior to cyclophosphamide in children with steroid-resistant nephrotic syndrome-a randomized controlled multicentre trial by the Arbeitsgemeinschaft fur Padiatrische Nephrologie. Pediat Nephrol (Berlin, Germany) 23(9):1483-1493. https://doi.org/10.1007/s00467-008-0794-1

57. Sinha A, Gupta A, Kalaivani M, Hari P, Dinda AK, Bagga A (2017) Mycophenolate mofetil is inferior to tacrolimus in sustaining remission in children with idiopathic steroid-resistant nephrotic syndrome. Pediat Nephrol (Berlin, Germany) 92(1):248-257. https://doi.org/10.1007/s00467-017-3634-3.10.1016/j.kint.2017. 01.019

58. Ponticelli C (1993) Cyclosporine in idiopathic nephrotic syndrome. Immunopharmacol Immunotoxicol 15(4):479-489. https://doi.org/10.3109/08923979309035241 
59. Cattran DC, Alexopoulos E, Heering P, Hoyer PF, Johnston A, Meyrier A, Ponticelli C, Saito T, Choukroun G, Nachman P, Praga M, Yoshikawa N (2007) Cyclosporin in idiopathic glomerular disease associated with the nephrotic syndrome : workshop recommendations. Kidney Int 72(12):1429-1447. https://doi.org/10. 1038/sj.ki.5002553

60. Tarshish P, Tobin JN, Bernstein J, Edelmann CM Jr (1996) Cyclophosphamide does not benefit patients with focal segmental glomerulosclerosis. A report of the International Study of Kidney Disease in Children. Pediat Nephrol (Berlin, Germany) 10(5): 590-593

61. Prospective, controlled trial of cyclophosphamide therapy in children with nephrotic syndrome. Report of the International study of Kidney Disease in Children (1974). Lancet (London, England) 2 (7878):423-427

62. Mantan M, Sriram CS, Hari P, Dinda A, Bagga A (2008) Efficacy of intravenous pulse cyclophosphamide treatment versus combination of intravenous dexamethasone and oral cyclophosphamide treatment in steroid-resistant nephrotic syndrome. Pediat Nephrol (Berlin, Germany) 23(9):1495-1502. https://doi.org/10.1007/ s00467-008-0860-8

63. Elhence R, Gulati S, Kher V, Gupta A, Sharma RK (1994) Intravenous pulse cyclophosphamide-a new regime for steroidresistant minimal change nephrotic syndrome. Pediatr Nephrol (Berlin, Germany) 8(1):1-3. https://doi.org/10.1007/bf00868243

64. Shah KM, Ohri AJ, Ali US (2017) A randomized controlled trial of intravenous versus oral cyclophosphamide in steroid-resistant nephrotic syndrome in children. Indian J Nephrol 27(6):430-434. https://doi.org/10.4103/ijn.IJN_201_16

65. Bajpai A, Bagga A, Hari P, Dinda A, Srivastava RN (2003) Intravenous cyclophosphamide in steroid-resistant nephrotic syndrome. Pediat Nephrol (Berlin, Germany) 18(4):351-356. https:// doi.org/10.1007/s00467-003-1095-3

66. Gulati S, Kher V (2000) Intravenous pulse cyclophosphamide-a new regime for steroid resistant focal segmental glomerulosclerosis. Indian Pediatr 37(2):141-148

67. Knight SR, Morris PJ (2007) The clinical benefits of cyclosporine C2-level monitoring: a systematic review. Transplantation 83(12): 1525-1535. https://doi.org/10.1097/01.tp.0000268306.41196.2c

68. Kengne-Wafo S, Massella L, Diomedi-Camassei F, Gianviti A, Vivarelli M, Greco M, Stringini GR, Emma F (2009) Risk factors for cyclosporin A nephrotoxicity in children with steroiddependant nephrotic syndrome. Clin J Am Soc Nephrol 4(9): 1409-1416. https://doi.org/10.2215/cjn.01520209

69. Dorresteijn EM, Kist-van Holthe JE, Levtchenko EN, Nauta J, Hop WC, van der Heijden AJ (2008) Mycophenolate mofetil versus cyclosporine for remission maintenance in nephrotic syndrome. Pediat Nephrol (Berlin, Germany) 23(11):2013-2020. https://doi.org/10.1007/s00467-008-0899-6

70. Uddin GMRM, Rahman MH, Roy RR, Begum A, Huque SS (2016) Comparative efficacy of mycophenolate mofetil and cyclosporine in children with frequent relapse nephrotic syndrome [abstract]. Pediatr Nephrol 31(10):1852-1853

71. Gellermann J, Ehrich JH, Querfeld U (2012) Sequential maintenance therapy with cyclosporin A and mycophenolate mofetil for sustained remission of childhood steroid-resistant nephrotic syndrome. Nephrol Dial Transplant 27(5):1970-1978. https://doi.org/ 10.1093/ndt/gfr572

72. Singh L, Singh G, Sharma A, Sinha A, Bagga A, Dinda AK (2015) A comparative study on renal biopsy before and after long-term calcineurin inhibitors therapy: an insight for pathogenesis of its toxicity. Hum Pathol 46(1):34-39. https://doi.org/10. 1016/j.humpath.2014.09.003

73. Niaudet P (1994) Treatment of childhood steroid-resistant idiopathic nephrosis with a combination of cyclosporine and prednisone. French Society of Pediatric Nephrology. J Pediatr 125(6 Pt 1):981-986. https://doi.org/10.1016/s0022-3476(05) 82020-7

74. Ehrich JH, Geerlings C, Zivicnjak M, Franke D, Geerlings H, Gellermann J (2007) Steroid-resistant idiopathic childhood nephrosis: overdiagnosed and undertreated. Nephrol Dial Transplant 22(8):2183-2193. https://doi.org/10.1093/ndt/gfm092

75. Bagga A, Sinha A, Moudgil A (2007) Rituximab in patients with the steroid-resistant nephrotic syndrome. N Engl J Med 356(26): 2751-2752. https://doi.org/10.1056/NEJMc063706

76. Nakayama M, Kamei K, Nozu K, Matsuoka K, Nakagawa A, Sako M, Iijima K (2008) Rituximab for refractory focal segmental glomerulosclerosis. Pediat Nephrol (Berlin, Germany) 23(3):481485. https://doi.org/10.1007/s00467-007-0640-x

77. Gulati A, Sinha A, Jordan SC, Hari P, Dinda AK, Sharma S, Srivastava RN, Moudgil A, Bagga A (2010) Efficacy and safety of treatment with rituximab for difficult steroid-resistant and dependent nephrotic syndrome: multicentric report. Clin J Am Soc Nephrol 5(12):2207-2212. https://doi.org/10.2215/cjn. 03470410

78. Ito S, Kamei K, Ogura M, Udagawa T, Fujinaga S, Saito M, Sako M, Iijima K (2013) Survey of rituximab treatment for childhoodonset refractory nephrotic syndrome. Pediat Nephrol (Berlin, Germany) 28(2):257-264. https://doi.org/10.1007/s00467-0122319-1

79. Kamei K, Ishikura K (2016) Rituximab treatment for refractory steroid-resistant nephrotic syndrome. Pediat Nephrol (Berlin, Germany) 31(2):337-338. https://doi.org/10.1007/s00467-0153205-4

80. Fujinaga S, Sakuraya K (2017) Repeated administrations of rituximab along with steroids and immunosuppressive agents in refractory steroid-resistant nephrotic syndrome. Indian Pediatr 54(1): 49-50. https://doi.org/10.1007/s13312-017-0996-3

81. Zachwieja J, Silska-Dittmar M (2018) Multicenter analysis of the efficacy and safety of a non-standard immunosuppressive therapy with rituximab in children with steroid-resistant nephrotic syndrome. doi:https://doi.org/10.1111/1440-1681.13046

82. Sun L, Xu H, Shen Q, Cao Q, Rao J, Liu HM, Fang XY, Zhou LJ (2014) Efficacy of rituximab therapy in children with refractory nephrotic syndrome: a prospective observational study in Shanghai. World J Pediatr 10(1):59-63. https://doi.org/10.1007/ s12519-014-0453-5

83. Kari JA, El-Morshedy SM, El-Desoky S, Alshaya HO, Rahim KA, Edrees BM (2011) Rituximab for refractory cases of childhood nephrotic syndrome. Pediat Nephrol (Berlin, Germany) 26(5):733-737. https://doi.org/10.1007/s00467-011-1778-0

84. Basu B, Mahapatra TK, Mondal N (2015) Mycophenolate mofetil following rituximab in children with steroid-resistant nephrotic syndrome. Pediatrics 136(1):e132-e139. https://doi.org/10.1542/ peds.2015-0486

85. Magnasco A, Ravani P, Edefonti A, Murer L, Ghio L, Belingheri M, Benetti E, Murtas C, Messina G, Massella L, Porcellini MG, Montagna M, Regazzi M, Scolari F, Ghiggeri GM (2012) Rituximab in children with resistant idiopathic nephrotic syndrome. J Am Soc Nephrol 23(6):1117-1124. https://doi.org/10. 1681/asn.2011080775

86. Fujinaga S, Nishino T, Umeda C, Tomii Y, Watanabe Y, Sakuraya K (2019) Long-term outcomes after early treatment with rituximab for Japanese children with cyclosporine- and steroid-resistant nephrotic syndrome. Pediat Nephrol (Berlin, Germany) 34(2):353357. https://doi.org/10.1007/s00467-018-4145-6

87. Kronbichler A, Gauckler P, Lee KH, Shin JI, Malvezzi P, Mayer G (2019) Immunoadsorption in nephrotic syndrome: where are we now and where are we going from here? Atheroscler Suppl. https://doi.org/10.1016/j.atherosclerosissup.2019.08.027 
88. Vivarelli M, Colucci M, Bonanni A, Verzani M, Serafinelli J, Emma F, Ghiggeri G (2017) Ofatumumab in two pediatric nephrotic syndrome patients allergic to rituximab. Pediat Nephrol (Berlin, Germany) 32(1):181-184. https://doi.org/10.1007/ s00467-016-3498-y

89. Wang CS (2017) Ofatumumab for the treatment of childhood nephrotic syndrome. F1000Research 32(5):835-841. https://doi.org/ 10.1007/s00467-017-3621-8

90. Basu B (2014) Ofatumumab for rituximab-resistant nephrotic syndrome. N Engl J Med 370(13):1268-1270. https://doi.org/10. 1056/NEJMc1308488

91. Muso E, Mune M, Hirano T, Hattori M, Kimura K, Watanabe T, Yokoyama H, Sato H, Uchida S, Wada T, Shoji T, Takemura T, Yuzawa Y, Ogahara S, Sugiyama S, Iino Y, Sakai S, Ogura Y, Yukawa S, Nishizawa Y, Yorioka N, Imai E, Matsuo S, Saito T (2015) A prospective observational survey on the long-term effect of LDL apheresis on drug-resistant nephrotic syndrome. Nephron Extra 5(2):58-66. https://doi.org/10.1159/000437338

92. Shah L (2019) LDL-apheresis-induced remission of focal segmental glomerulosclerosis recurrence in pediatric renal transplant recipients. Int J Genom. https://doi.org/10.1155/2019/2197837.10. 1007/s00467-019-04296-6

93. Raina R, Krishnappa V (2019) An update on LDL apheresis for nephrotic syndrome. Pediat Nephrol (Berlin, Germany) 34(10): 1655-1669. https://doi.org/10.1007/s00467-018-4061-9

94. Yu CC, Fornoni A, Weins A, Hakroush S, Maiguel D, Sageshima J, Chen L, Ciancio G, Faridi MH, Behr D, Campbell KN, Chang JM, Chen HC, Oh J, Faul C, Arnaout MA, Fiorina P, Gupta V, Greka A, Burke GW 3rd, Mundel P (2013) Abatacept in B7-1positive proteinuric kidney disease. N Engl J Med 369(25):24162423. https://doi.org/10.1056/NEJMoa1304572

95. Jayaraman VK (2016) Thomas M (2016) Abatacept experience in steroid and rituximab-resistant focal segmental glomerulosclerosis. BMJ Case Reports. https://doi.org/10.1136/ bcr-2016-214396

96. Dado D, Parikh S, Ayoub I, Rovin B, Nadasdy T, Hebert L (2018) Abatacept efficacy in steroid-resistant minimal-change disease revealed by the speed of proteinuria reduction after the start of abatacept. Clin Nephrol 89(5):376-380. https://doi.org/10.5414/ cn109290

97. Mishra OP, Singh AK (2014) Galactose treatment in focal and segmental glomerulosclerosis. Pediat Nephrol (Berlin, Germany) 29(5):935. https://doi.org/10.1007/s00467-013-2731-1

98. Sgambat K, Banks M, Moudgil A (2013) Effect of galactose on glomerular permeability and proteinuria in steroid-resistant nephrotic syndrome. Pediatr Nephrol (Berlin, Germany) 28(11): 2131-2135. https://doi.org/10.1007/s00467-013-2539-z

99. Trachtman H, Savin VJ (2014) Galactose treatment in focal segmental glomerulosclerosis. Pediat Nephrol (Berlin, Germany) 29(5):931. https://doi.org/10.1007/s00467-013-2700-8

100. Trautmann A, Schnaidt S, Lipska-Zietkiewicz BS, Bodria M, Ozaltin F, Emma F, Anarat A, Melk A, Azocar M, Oh J, Saeed B, Gheisari A, Caliskan S, Gellermann J, Higuita LMS, Jankauskiene A, Drozdz D, Mir S, Balat A, Szczepanska M, Paripovic D, Zurowska A, Bogdanovic R, Yilmaz A, Ranchin B, Baskin E, Erdogan O, Remuzzi G, Firszt-Adamczyk A, Kuzma-Mroczkowska E, Litwin M, Murer L, Tkaczyk M, Jardim H, Wasilewska A, Printza N, Fidan K, Simkova E, Borzecka H, Staude H, Hees K, Schaefer F (2017) Long-term outcome of steroid-resistant nephrotic syndrome in children. Biomed Res Int 28(10):3055-3065. https://doi.org/10.1681/asn. 2016101121

101. Buscher AK, Beck BB, Melk A, Hoefele J, Kranz B, Bamborschke D, Baig S, Lange-Sperandio B, Jungraithmayr T, Weber LT, Kemper MJ, Tonshoff B, Hoyer PF, Konrad M, Weber S (2016) Rapid response to Cyclosporin A and favorable renal outcome in nongenetic versus genetic steroid-resistant nephrotic syndrome. Clin J Am Soc Nephrol 11(2):245-253. https://doi. org/10.2215/cjn.07370715

102. Buscher AK, Kranz B, Buscher R, Hildebrandt F, Dworniczak B, Pennekamp P, Kuwertz-Broking E, Wingen AM, John U, Kemper M, Monnens L, Hoyer PF, Weber S, Konrad M (2010) Immunosuppression and renal outcome in congenital and pediatric steroid-resistant nephrotic syndrome. Clin J Am Soc Nephrol 5(11):2075-2084. https://doi.org/10.2215/cjn.01190210

103. Starr MC, Chang IJ, Finn LS, Sun A, Larson AA, Goebel J, Hanevold C, Thies J, Van Hove JLK, Hingorani SR, Lam C (2018) COQ2 nephropathy: a treatable cause of nephrotic syndrome in children. Pediat Nephrol (Berlin, Germany) 33(7): 1257-1261. https://doi.org/10.1007/s00467-018-3937-z

104. Eroglu FK, Ozaltin F, Gonc N, Nalcacioglu H, Ozcakar ZB, Yalnizoglu D, Gucer S, Orhan D, Eminoglu FT, Gocmen R, Alikasifoglu A, Topaloglu R, Duzova A (2018) Response to early coenzyme Q10 supplementation is not sustained in CoQ10 deficiency caused by CoQ2 mutation. Pediatr Neurol 88:71-74. https://doi.org/10.1016/j.pediatrneurol.2018.07.008

105. Atmaca M, Gulhan B, Korkmaz E, Inozu M, Soylemezoglu O, Candan C, Bayazit AK, Elmaci AM, Parmaksiz G, Duzova A, Besbas N, Topaloglu R, Ozaltin F (2017) Follow-up results of patients with ADCK4 mutations and the efficacy of CoQ10 treatment 32(8):1369-1375. doi:https://doi.org/10.1007/s00467-0173634-3

106. Lieberman KV, Pavlova-Wolf A (2017) Adrenocorticotropic hormone therapy for the treatment of idiopathic nephrotic syndrome in children and young adults: a systematic review of early clinical studies with contemporary relevance. J Nephrol 30(1):35-44. https://doi.org/10.1007/s40620-016-0308-3

107. Awanami Y, Fukuda M, Nonaka Y, Takashima T, Matsumoto K, Yamasaki M, Miyazono M, Ikeda Y (2017) Successful treatment of a patient with refractory nephrotic syndrome with PCSK9 inhibitors: a case report. BMC Nephrol 18(1):221. https://doi.org/ 10.1186/s12882-017-0644-0

108. Suzuki H, Tsukamoto T, Muso E (2017) Rituximab-resistant nephrotic syndrome with successful induction of remission by lowdensity lipoprotein apheresis. Ther Apher Dial 21(3):295-296. https://doi.org/10.1111/1744-9987.12561

109. Bockenhauer D (2013) Over- or underfill: not all nephrotic states are created equal. Pediat Nephrol (Berlin, Germany) 28(8):11531156. https://doi.org/10.1007/s00467-013-2435-6

110. Cadnapaphornchai MA, Tkachenko O, Shchekochikhin D, Schrier RW (2014) The nephrotic syndrome: pathogenesis and treatment of edema formation and secondary complications. Pediat Nephrol (Berlin, Germany) 29(7):1159-1167. https://doi. org/10.1007/s00467-013-2567-8

111. Schrier RW, Fassett RG (1998) A critique of the overfill hypothesis of sodium and water retention in the nephrotic syndrome. Kidney Int 53(5):1111-1117. https://doi.org/10.1046/j.15231755.1998.00864.x

112. Vande Walle JG, Donckerwolcke RA, Koomans HA (1999) Pathophysiology of edema formation in children with nephrotic syndrome not due to minimal change disease. J Am Soc Nephrol 10(2):323-331

113. Kapur G, Valentini RP, Imam AA, Mattoo TK (2009) Treatment of severe edema in children with nephrotic syndrome with diuretics alone-a prospective study. Clin J Am Soc Nephrol 4(5):907-913. https://doi.org/10.2215/cjn.04390808

114. McCaffrey J, Lennon R, Webb NJ (2016) The nonimmunosuppressive management of childhood nephrotic syndrome. Pediat Nephrol (Berlin, Germany) 31(9):1383-1402. https://doi.org/10.1007/s00467-015-3241-0

115. Rheault MN, Zhang L, Selewski DT, Kallash M, Tran CL, Seamon M, Katsoufis C, Ashoor I, Hernandez J, Supe- 
Markovina K, D'Alessandri-Silva C, DeJesus-Gonzalez N, Vasylyeva TL, Formeck C, Woll C, Gbadegesin R, Geier P, Devarajan P, Carpenter SL, Kerlin BA, Smoyer WE (2015) AKI in children hospitalized with nephrotic syndrome. Clin J Am Soc Nephrol 10(12):2110-2118. https://doi.org/10.2215/cjn. 06620615

116. Gupta S, Pepper RJ, Ashman N, Walsh SB (2018) Nephrotic syndrome: oedema formation and its treatment with diuretics. Front Physiol 9:1868. https://doi.org/10.3389/fphys.2018.01868

117. Fallahzadeh MA, Dormanesh B, Fallahzadeh MK, Roozbeh J, Fallahzadeh MH, Sagheb MM (2017) Acetazolamide and hydrochlorothiazide followed by furosemide versus furosemide and hydrochlorothiazide followed by furosemide for the treatment of adults with nephrotic edema: a randomized trial. Am J Kidney Dis 69(3):420-427. https://doi.org/10.1053/j.ajkd.2016.10.022

118. Lemieux G, Beauchemin M, Gougoux A, Vinay P (1981) Treatment of nephrotic edema with bumetanide. Can Med Assoc J 125(10):1111-1112 1117

119. Garin EH (1987) A comparison of combinations of diuretics in nephrotic edema. Am J Dis Children (1960) 141(7):769-771. https://doi.org/10.1001/archpedi.1987.04460070071028

120. Mahdavinia SOH, Hoseini R, Shheikhvatan M (2016) Amiloride vs hydrochlorthiazide therapy in children with ne- phrotic syndrome: a clinical trial. Int J Children Adolesc 2(3):29-31

121. Prandota $\mathbf{J}$ (1983) Pharmacokinetics of furosemide urinary elimination by nephrotic children. Pediatr Res 17(2):141-147. https:// doi.org/10.1203/00006450-198302000-00012

122. Engle MA, Lewy JE, Lewy PR, Metcoff J (1978) The use of furosemide in the treatment of edema in infants and children. Pediatrics 62(5):811-818

123. Fliser D, Zurbruggen I, Mutschler E, Bischoff I, Nussberger J, Franek E, Ritz E (1999) Coadministration of albumin and furosemide in patients with the nephrotic syndrome. Kidney Int 55(2): 629-634. https://doi.org/10.1046/j.1523-1755.1999.00298.x

124. Dharmaraj R, Hari P, Bagga A (2009) Randomized cross-over trial comparing albumin and frusemide infusions in nephrotic syndrome. Pediat Nephrol (Berlin, Germany) 24(4):775-782. https://doi.org/10.1007/s00467-008-1062-0

125. Kitsios GD, Mascari P, Ettunsi R, Gray AW (2014) Coadministration of furosemide with albumin for overcoming diuretic resistance in patients with hypoalbuminemia: a meta-analysis. $\mathrm{J}$ Crit Care 29(2):253-259. https://doi.org/10.1016/j.jcrc.2013.10. 004

126. Haws RM, Baum M (1993) Efficacy of albumin and diuretic therapy in children with nephrotic syndrome. Pediatrics 91(6):11421146

127. Liumbruno GM, Bennardello F, Lattanzio A, Piccoli P, Rossettias $\mathrm{G}$ (2009) Recommendations for the use of albumin and immunoglobulins. Blood Transfus 7(3):216-234. https://doi.org/10.2450/ 2009.0094-09

128. Reid CJ, Marsh MJ, Murdoch IM, Clark G (1996) Nephrotic syndrome in childhood complicated by life threatening pulmonary oedema. BMJ (Clin Res ed) 312(7022):36-38. https://doi.org/10. 1136/bmj.312.7022.36

129. Rodrigo R, Bravo I, Pino M (1996) Proteinuria and albumin homeostasis in the nephrotic syndrome: effect of dietary protein intake. Nutr Rev 54(11 Pt 1):337-347. https://doi.org/10.1111/j. 1753-4887.1996.tb03800.x

130. Sethna CB, Ng DK, Jiang S, Saland J, Warady BA, Furth S, Meyers KE (2019) Cardiovascular disease risk among children with focal segmental glomerulosclerosis: a report from the chronic kidney disease in children study. Pediat Nephrol (Berlin, Germany) 34(8):1403-1412. https://doi.org/10.1007/s00467019-04229-3

131. Ribeiro D, Zawadynski S, Pittet LF, Chevalley T, Girardin E, Parvex P (2015) Effect of glucocorticoids on growth and bone mineral density in children with nephrotic syndrome. Eur J Pediatr 174(7):911-917. https://doi.org/10.1007/s00431-0142479-z

132. Lee JM, Kronbichler A (2019) Review on long-term non-renal complications of childhood nephrotic syndrome. https://doi.org/ 10.1111/apa.15035

133. KDOQI Clinical Practice Guideline for Nutrition in Children with CKD: 2008 update. Executive summary (2009). American Journal of Kidney Diseases 53 (3 Suppl 2):S11-104. doi:https://doi.org/ 10.1053/j.ajkd.2008.11.017

134. McAlister L, Pugh P, Greenbaum L, Haffner D, Rees L, Anderson C, Desloovere A, Nelms C, Oosterveld M, Paglialonga F, Polderman N, Qizalbash L, Renken-Terhaerdt J, Tuokkola J, Warady B, Walle JV, Shaw V, Shroff R (2019) The dietary management of calcium and phosphate in children with CKD stages 25 and on dialysis-clinical practice recommendation from the Pediatric Renal Nutrition Taskforce. doi:https://doi.org/10.1007/ s00467-019-04370-z

135. Ljungberg P, Holmberg C, Jalanko H (1997) Infections in infants with congenital nephrosis of the Finnish type. Pediat Nephrol (Berlin, Germany) 11(2):148-152. https://doi.org/10.1007/ s004670050246

136. Karim MYBBP (2018) Hypogammglobulinemia. BMJ Best Practices (bestpracticesbmjcom) Mar 21, 2018

137. Minimal change nephrotic syndrome in children: Deaths during the first 5 to 15 years' observation. Report of the International Study of Kidney Disease in Children (1984). Pediatrics 73(4): 497-501

138. Pasini A, Benetti E, Conti G, Ghio L, Lepore M, Massella L, Molino D, Peruzzi L, Emma F, Fede C, Trivelli A, Maringhini S, Materassi M, Messina G, Montini G, Murer L, Pecoraro C, Pennesi M (2017) The Italian Society for Pediatric Nephrology ( $\mathrm{SINePe}$ ) consensus document on the management of nephrotic syndrome in children: part I - diagnosis and treatment of the first episode and the first relapse. Ital J Pediatr 43(1):41. https://doi.org/ 10.1186/s13052-017-0356-x

139. Nuorti JP, Whitney CG (2010) Prevention of pneumococcal disease among infants and children - use of 13-valent pneumococcal conjugate vaccine and 23 -valent pneumococcal polysaccharide vaccine - recommendations of the Advisory Committee on Immunization Practices (ACIP). MMWR Recommendations and reports : Morbidity and mortality weekly report Recommendations and reports $59(\mathrm{Rr}-11): 1-18$

140. Gipson DS, Massengill SF, Yao L, Nagaraj S, Smoyer WE, Mahan JD, Wigfall D, Miles P, Powell L, Lin JJ, Trachtman H, Greenbaum LA (2009) Management of childhood onset nephrotic syndrome. Pediatrics 124(2):747-757. https://doi.org/10.1542/ peds.2008-1559

141. Wu HM, Tang JL, Cao L, Sha ZH, Li Y (2012) Interventions for preventing infection in nephrotic syndrome. The Cochrane Database of Systematic Reviews (4):Cd003964. doi:https://doi. org/10.1002/14651858.CD003964.pub3

142. Bagga A (2008) Revised guidelines for management of steroidsensitive nephrotic syndrome. Indian J Nephrol 18(1):31-39. https://doi.org/10.4103/0971-4065.41289

143. Uncu N, Bulbul M, Yildiz N, Noyan A, Kosan C, Kavukcu S, Caliskan S, Gunduz Z, Besbas N, Gur Guven A (2010) Primary peritonitis in children with nephrotic syndrome: results of a 5-year multicenter study. Eur J Pediatr 169(1):73-76. https://doi.org/10. 1007/s00431-009-0989-x

144. Gorensek MJ, Lebel MH, Nelson JD (1988) Peritonitis in children with nephrotic syndrome. Pediatrics 81(6):849-856

145. Krensky AM, Ingelfinger JR, Grupe WE (1982) Peritonitis in childhood nephrotic syndrome: 1970-1980. Am J Dis Children (1960) 136(8):732-736. https://doi.org/10.1001/archpedi.1982. 03970440076023 
146. Gulati S, Kher V, Arora P, Gupta S, Kale S (1996) Urinary tract infection in nephrotic syndrome. Pediatr Infect Dis J 15(3):237240. https://doi.org/10.1097/00006454-199603000-00012

147. McIntyre P, Craig JC (1998) Prevention of serious bacterial infection in children with nephrotic syndrome. J Paediatr Child Health 34(4):314-317. https://doi.org/10.1046/j.1440-1754.1998.00232.

148. HHS (2016) HHS Panel on Opportunistic Infections in HIVExposed and HIV-Infected Children. Guidelines for the Prevention and Treatment of Opportunistic Infections in HIVExposed and HIV-Infected Children. Department of Health and Human Services Available at http://aidsinfonih.gov/contentfiles/ lvguidelines/oi_guidelines_pediatrics.pdf Accessed 2016

149. HHS (2017) HHS Panel on Guidelines for the Prevention and Treatment of Opportunistic Infections in Adults and Adolescents with HIV. Guidelines for the Prevention and Treatment of Opportunistic Infections in HIV-infected Adults and Adolescents: Recommendations from the Centers for Disease Control and Prevention, the National Institutes of Health, and the HIV Medicine Association of the Infectious Diseases Society of America. Available at http://aidsinfonih.gov/contentfiles/ lvguidelines/adult oi.pdf. Accessed 2017

150. FDA approval of an extended period for administering VariZIG for postexposure prophylaxis of varicella (2012). MMWR Morbidity and mortality weekly report 61(12):212

151. Updated recommendations for use of VariZIG-United States, 2013 (2013). MMWR Morb Mortal Wkly Rep 62 (28):574-576

152. Administration FaD (2012) FDA approves VariZIG for reducing chickenpox symptoms. Food and Drug Administration, Silver Spring, p 2012

153. Marin M, Guris D, Chaves SS, Schmid S, Seward JF (2007) Prevention of varicella: recommendations of the Advisory Committee on Immunization Practices (ACIP). MMWR Recommendations and reports : morbidity and mortality weekly report. Recommen Reports 56(Rr-4):1-40

154. Levin MJ, Duchon JM, Swamy GK, Gershon AA (2019) Varicella zoster immune globulin (VARIZIG) administration up to 10 days after varicella exposure in pregnant women, immunocompromised participants, and infants: varicella outcomes and safety results from a large, open-label, expanded-access program. PLoS One 14(7):e0217749. https://doi.org/10.1371/journal.pone. 0217749

155. Lin TY, Huang YC, Ning HC, Hsueh C (1997) Oral acyclovir prophylaxis of varicella after intimate contact. Pediatr Infect Dis J 16(12):1162-1165. https://doi.org/10.1097/00006454199712000-00012

156. Asano Y, Yoshikawa T, Suga S, Kobayashi I, Nakashima T, Yazaki T, Ozaki T, Yamada A, Imanishi J (1993) Postexposure prophylaxis of varicella in family contact by oral acyclovir. Pediatrics 92(2):219-222

157. Goldstein SL, Somers MJ, Lande MB, Brewer ED, Jabs KL (2000) Acyclovir prophylaxis of varicella in children with renal disease receiving steroids. Pediat Nephrol (Berlin, Germany) 14(4):305-308. https://doi.org/10.1007/s004670050764

158. Kerlin BA, Haworth K, Smoyer WE (2014) Venous thromboembolism in pediatric nephrotic syndrome. Pediat Nephrol (Berlin, Germany) 29(6):989-997. https://doi.org/10.1007/s00467-0132525-5

159. Andrew M, Brooker LA (1996) Hemostatic complications in renal disorders of the young. Pediat Nephrol (Berlin, Germany) 10(1): 88-99. https://doi.org/10.1007/bf00863459

160. Lilova MI, Velkovski IG, Topalov IB (2000) Thromboembolic complications in children with nephrotic syndrome in Bulgaria (1974-1996). Pediat Nephrol (Berlin, Germany) 15(1-2):74-78. https://doi.org/10.1007/s004679900253
161. Carpenter SL, Goldman J, Sherman AK, Selewski DT, Kallash M, Tran CL, Seamon M, Katsoufis C, Ashoor I, Hernandez J, SupeMarkovina K, D'Alessandri-Silva C, DeJesus-Gonzalez N, Vasylyeva TL, Formeck C, Woll C, Gbadegesin R, Geier P, Devarajan P, Smoyer WE, Kerlin BA, Rheault MN (2019) Association of infections and venous thromboembolism in hospitalized children with nephrotic syndrome. 34(2):261-267. doi: https://doi.org/10.1007/s00467-018-4072-6

162. Agrawal S, Zaritsky JJ, Fornoni A, Smoyer WE (2018) Dyslipidaemia in nephrotic syndrome: mechanisms and treatment. Nat Rev Nephrol 14(1):57-70. https://doi.org/10.1038/ nrneph.2017.155

163. Kong X, Yuan H, Fan J, Li Z, Wu T, Jiang L (2013) Lipidlowering agents for nephrotic syndrome. The Cochrane database of systematic reviews (12):Cd005425. doi:https://doi.org/10. 1002/14651858.CD005425.pub2

164. Suryawanshi SP, Das B, Patnaik AN (2011) Myocardial infarction in children: two interesting cases. Ann Pediatr Cardiol 4(1):81-83. https://doi.org/10.4103/0974-2069.79633

165. Silva JM, Oliveira EA, Marino VS, Oliveira JS, Torres RM, Ribeiro AL, Simal CJ, Ribeiro MC (2002) Premature acute myocardial infarction in a child with nephrotic syndrome. Pediat Nephrol (Berlin, Germany) 17(3):169-172. https://doi.org/10. 1007/s00467-001-0793-y

166. Hari P, Khandelwal P, Smoyer WE (2019) Dyslipidemia and cardiovascular health in childhood nephrotic syndrome. Pediatr Nephrol (Berlin). https://doi.org/10.1007/s00467-019-04301-y

167. Coleman JE, Watson AR (1996) Hyperlipidaemia, diet and simvastatin therapy in steroid-resistant nephrotic syndrome of childhood. Pediat Nephrol (Berlin, Germany) 10(2):171-174. https:// doi.org/10.1007/bf00862065

168. Sanjad SA, al-Abbad A, al-Shorafa S (1997) Management of hyperlipidemia in children with refractory nephrotic syndrome: the effect of statin therapy. J Pediatr 130(3):470-474. https://doi.org/ 10.1016/s0022-3476(97)70213-0

169. Hari P, Khandelwal P, Satpathy A, Hari S, Thergaonkar R, Lakshmy R, Sinha A, Bagga A (2018) Effect of atorvastatin on dyslipidemia and carotid intima-media thickness in children with refractory nephrotic syndrome: a randomized controlled trial. Pediat Nephrol (Berlin, Germany) 33(12):2299-2309. https:// doi.org/10.1007/s00467-018-4036-x

170. Nishi S, Ubara Y, Utsunomiya Y, Okada K, Obata Y, Kai H, Kiyomoto H, Goto S, Konta T, Sasatomi Y, Sato Y, Nishino T, Tsuruya K, Furuichi K, Hoshino J, Watanabe Y, Kimura K, Matsuo S (2016) Evidence-based clinical practice guidelines for nephrotic syndrome 2014. Clin Exp Nephrol 20(3):342-370. https://doi.org/10.1007/s10157-015-1216-x

171. Alon U, Chan JC (1984) Calcium and vitamin D homeostasis in the nephrotic syndrome: current status. Nephron 36(1):1-4. https://doi.org/10.1159/000183106

172. Selewski DT, Chen A, Shatat IF, Pais P, Greenbaum LA, Geier P, Nelson RD, Kiessling SG, Brophy PD, Quiroga A, Seifert ME, Straatmann CE, Mahan JD, Ferris ME, Troost JP, Gipson DS (2016) Vitamin D in incident nephrotic syndrome: a Midwest Pediatric Nephrology Consortium study. Pediat Nephrol (Berlin, Germany) 31(3):465-472. https://doi.org/10.1007/s00467-0153236-x

173. Denburg MR (2016) Skeletal manifestations of renal disease in childhood. Curr Opin Nephrol Hypertens 25(4):292-300. https:// doi.org/10.1097/mnh.0000000000000233

174. Singh DN, Krishnamurthy S, Kamalanathan SK, Harichandrakumar KT, Sivamurukan P (2018) Three-monthly bolus vitamin D supplements (1000 vs 400 IU/day) for prevention of bone loss in children with difficult-to-treat nephrotic syndrome: a randomised clinical trial. Paediatr Int Child Health 
38(4):251-260. https://doi.org/10.1080/20469047.2018. 1505589

175. Shroff R, Wan M, Nagler EV, Bakkaloglu S, Cozzolino M, Bacchetta J, Edefonti A, Stefanidis CJ, Vande Walle J, Ariceta G, Klaus G, Haffner D, Schmitt CP (2017) Clinical practice recommendations for treatment with active vitamin $\mathrm{D}$ analogues in children with chronic kidney disease stages 2-5 and on dialysis. Nephrol Dial Transplant 32(7):1114-1127. https://doi.org/10. 1093/ndt/gfx080

176. Ito S, Kano K, Ando T, Ichimura T (1994) Thyroid function in children with nephrotic syndrome. Pediat Nephrol (Berlin, Germany) 8(4):412-415. https://doi.org/10.1007/bf00856516

177. Dagan A, Cleper R, Krause I, Blumenthal D, Davidovits M (2012) Hypothyroidism in children with steroid-resistant nephrotic syndrome. Nephrol Dial Transplant 27(6):2171-2175. https://doi.org/ 10.1093/ndt/gfr665

178. Kapoor K, Saha A, Dubey NK, Goyal P, Suresh CP, Batra V, Upadhayay AD (2014) Subclinical non-autoimmune hypothyroidism in children with steroid resistant nephrotic syndrome. Clin Exp Nephrol 18(1):113-117. https://doi.org/10.1007/ s10157-013-0800-1

179. Sharma S, Dabla PK, Kumar M (2015) Evaluation of thyroid hormone status in children with steroid resistant nephrotic syndrome: a North India study. Endocr Metab Immune Disord Drug Targets 15(4):321-324

180. Vigone MC, Capalbo D, Weber G, Salerno M (2018) Mild hypothyroidism in childhood: who, when, and how should be treated? J Endocrine Soc 2(9):1024-1039. https://doi.org/10.1210/js.201700471

181. Salerno M, Capalbo D, Cerbone M, De Luca F (2016) Subclinical hypothyroidism in childhood - current knowledge and open issues. Nat Rev Endocrinol 12(12):734-746. https://doi.org/10.1038/ nrendo.2016.100

182. Lurbe E, Cifkova R, Cruickshank JK, Dillon MJ, Ferreira I, Invitti C, Kuznetsova T, Laurent S, Mancia G, Morales-Olivas F, Rascher W, Redon J, Schaefer F, Seeman T, Stergiou G, Wuhl E, Zanchetti A (2009) Management of high blood pressure in children and adolescents: recommendations of the European Society of Hypertension. J Hypertens 27(9):1719-1742. https://doi.org/10. 1097/HJH.0b013e32832f4f6b

183. Lurbe E, Agabiti-Rosei E, Cruickshank JK, Dominiczak A, Erdine S, Hirth A, Invitti C, Litwin M, Mancia G, Pall D, Rascher W, Redon J, Schaefer F, Seeman T, Sinha M, Stabouli S, Webb NJ, Wuhl E, Zanchetti A (2016) 2016 European Society of Hypertension guidelines for the management of high blood pressure in children and adolescents. J Hypertens 34(10):1887-1920. https://doi.org/10.1097/hjh.0000000000001039

184. Ketteler M, Block GA, Evenepoel P, Fukagawa M, Herzog CA, McCann L, Moe SM, Shroff R, Tonelli MA, Toussaint ND, Vervloet MG, Leonard MB (2017) Executive summary of the 2017 KDIGO Chronic Kidney Disease-Mineral and Bone Disorder (CKD-MBD) Guideline Update: what's changed and why it matters. Kidney Int 92(1):26-36. https://doi.org/10.1016/ j.kint.2017.04.006

185. Hamasaki Y, Yoshikawa N, Hattori S, Sasaki S, Iijima K, Nakanishi K, Matsuyama T, Ishikura K, Yata N, Kaneko T, Honda M (2009) Cyclosporine and steroid therapy in children with steroid-resistant nephrotic syndrome. Pediat Nephrol (Berlin, Germany) 24(11):2177-2185. https://doi.org/10.1007/ s00467-009-1264-0

186. Prasad N, Manjunath R, Rangaswamy D, Jaiswal A, Agarwal V, Bhadauria D, Kaul A, Sharma R, Gupta A (2018) Efficacy and safety of cyclosporine versus tacrolimus in steroid and cyclophosphamide resistant nephrotic syndrome: a prospective study. Indian J Nephrol 28(1):46-52. https://doi.org/10.4103/ijn.IJN_240_16
187. Montane B, Abitbol C, Chandar J, Strauss J, Zilleruelo G (2003) Novel therapy of focal glomerulosclerosis with mycophenolate and angiotensin blockade. Pediat Nephrol (Berlin, Germany) 18(8):772-777. https://doi.org/10.1007/s00467-003-1174-5

188. Feltran LS, Varela P, Silva ED, Veronez CL, Franco MC, Filho AP, Camargo MF, Koch Nogueira PC, Pesquero JB (2017) Targeted next-generation sequencing in Brazilian children with nephrotic syndrome submitted to renal transplant. Transplantation 101(12): 2905-2912. https://doi.org/10.1097/tp.0000000000001846

189. Ding WY, Koziell A, McCarthy HJ, Bierzynska A, Bhagavatula MK, Dudley JA, Inward CD, Coward RJ, Tizard J, Reid C, Antignac C, Boyer O, Saleem MA (2014) Initial steroid sensitivity in children with steroid-resistant nephrotic syndrome predicts post-transplant recurrence. J Am Soc Nephrol 25(6):1342-1348. https://doi.org/10.1681/asn.2013080852

190. Kim SJ, Ha J, Jung IM, Ahn MS, Kim M, Lee HS, Cheong HI, Choi Y (2001) Recurrent focal segmental glomerulosclerosis following renal transplantation in Korean pediatric patients. Pediatr Transplant 5(2): 105-111

191. Francis A, Didsbury M, McCarthy H, Kara T (2018) Treatment of recurrent focal segmental glomerulosclerosis post-kidney transplantation in Australian and New Zealand children: a retrospective cohort study. Pediatr Transplant 22(5):e13185. https://doi.org/10. 1111/petr.13185

192. Briganti EM, Russ GR, McNeil JJ, Atkins RC, Chadban SJ (2002) Risk of renal allograft loss from recurrent glomerulonephritis. $\mathrm{N}$ Engl J Med 347(2):103-109. https://doi.org/10.1056/ NEJMoa013036

193. Lentine KL, Kasiske BL, Levey AS, Adams PL, Alberu J, Bakr MA, Gallon L, Garvey CA, Guleria S, Li PK, Segev DL, Taler SJ, Tanabe K, Wright L, Zeier MG, Cheung M, Garg AX (2017) KDIGO Clinical Practice Guideline on the Evaluation and Care of Living Kidney Donors. Transplantation 101(8S Suppl 1):S1s109. https://doi.org/10.1097/tp.0000000000001769

194. Andrews PA, Burnapp L, Manas D, Bradley JA, Dudley C (2012) Summary of the British Transplantation Society/Renal Association U.K. guidelines for living donor kidney transplantation. Transplantation 93(7):666-673. https://doi.org/10.1097/TP. 0b013e318247a $7 \mathrm{~b} 7$

195. Gross O, Weber M, Fries JW, Muller GA (2009) Living donor kidney transplantation from relatives with mild urinary abnormalities in Alport syndrome: long-term risk, benefit and outcome. Nephrol Dial Transplant 24(5):1626-1630. https://doi.org/10. 1093/ndt/gfn635

196. Hildebrandt F, Heeringa SF (2009) Specific podocin mutations determine age of onset of nephrotic syndrome all the way into adult life. Kidney Int 75(7):669-671. https://doi.org/10.1038/ki. 2008.693

197. Straner P, Balogh E, Schay G, Arrondel C, Miko A, L'Aune G, Benmerah A, Perczel A, D KM, Antignac C, Mollet G, Tory K (2018) C-terminal oligomerization of podocin mediates interallelic interactions. Biochim Biophys Acta Mol basis Dis 1864(7):2448 2457. https://doi.org/10.1016/j.bbadis.2018.04.008

198. Trachtman R, Sran SS, Trachtman H (2015) Recurrent focal segmental glomerulosclerosis after kidney transplantation. Pediat Nephrol (Berlin, Germany) 30(10):1793-1802. https://doi.org/ 10.1007/s00467-015-3062-1

199. Striegel JE, Sibley RK, Fryd DS, Mauer SM (1986) Recurrence of focal segmental sclerosis in children following renal transplantation. Kidney Int Suppl 19:S44-S50

200. Lee SE, Min SI, Kim YS, Ha J, Ha IS, Cheong HI, Kim SJ, Choi Y, Kang HG (2014) Recurrence of idiopathic focal segmental glomerulosclerosis after kidney transplantation: experience of a Korean tertiary center. Pediatr Transplant 18(4):369-376. https:// doi.org/10.1111/petr.12257 
201. Donckerwolcke RA, Broyer M, Brunner FP, Brynger H, Jacobs C, Kramer P, Selwood NH, Wing AJ (1983) Combined report on regular dialysis and transplantation of children in Europe, XI, 1981. Proc Eur Dial Transpl Assoc Eur Dial Transpl Assoc 19: 61-91

202. Cameron JS, Senguttuvan P, Hartley B, Rigden SP, Chantler C, Koffman G, Williams DG, Ogg CS (1989) Focal segmental glomerulosclerosis in fifty-nine renal allografts from a single centre; analysis of risk factors for recurrence. Transplant Proc 21(1 Pt 2):2117-2118

203. Moroni G, Gallelli B, Quaglini S, Banfi G, Montagnino G, Messa $P$ (2010) Long-term outcome of renal transplantation in adults with focal segmental glomerulosclerosis. Transpl Int 23(2):208216. https://doi.org/10.1111/j.1432-2277.2009.00977.x

204. Newstead CG (2003) Recurrent disease in renal transplants. Nephrol Dial Transplant 18 Suppl 6:vi68-vi74. https://doi.org/ $10.1093 / \mathrm{ndt} / \mathrm{gfg} 1068$

205. Garrouste C, Canaud G, Buchler M, Rivalan J, Colosio C, Martinez F, Aniort J, Dudreuilh C, Pereira B, Caillard S, Philipponnet C, Anglicheau D, Heng AE (2017) Rituximab for recurrence of primary focal segmental glomerulosclerosis after kidney transplantation: clinical outcomes. Transplantation 101(3):649-656. https://doi.org/10.1097/tp.0000000000001160

206. Kashgary A, Sontrop JM, Li L, Al-Jaishi AA, Habibullah ZN, Alsolaimani R, Clark WF (2016) The role of plasma exchange in treating post-transplant focal segmental glomerulosclerosis: a systematic review and meta-analysis of 77 case-reports and caseseries. BMC Nephrol 17(1):104. https://doi.org/10.1186/s12882016-0322-7

207. Sener A, Bella AJ, Nguan C, Luke PP, House AA (2009) Focal segmental glomerular sclerosis in renal transplant recipients: predicting early disease recurrence may prolong allograft function. Clin Transpl 23(1):96-100. https://doi.org/10.1111/j.1399-0012. 2008.00908.x

208. Fencl F, Vondrak K, Rosik T, Zieg J, Chadimova M, Hacek J, Dusek J, Seeman T (2016) Recurrence of nephrotic proteinuria in children with focal segmental glomerulosclerosis: early treatment with plasmapheresis and immunoadsorption should be associated with better prognosis. Minerva Pediatr 68(5):348-354

209. Ingulli E, Tejani A (1991) Incidence, treatment, and outcome of recurrent focal segmental glomerulosclerosis posttransplantation in 42 allografts in children-a single-center experience. Transplantation 51(2):401-405. https://doi.org/10.1097/ 00007890-199102000-00025

210. Staeck O, Halleck F, Budde K, Khadzhynov D (2017) Long-term outcomes of kidney transplant recipients with primary idiopathic focal segmental glomerulosclerosis. Transplant Proc 49(10): 2256-2259. https://doi.org/10.1016/j.transproceed.2017.10.001

211. Francis A, Trnka P, McTaggart SJ (2016) Long-term outcome of kidney transplantation in recipients with focal segmental glomerulosclerosis. Clin J Am Soc Nephrol 11(11):2041-2046. https://doi.org/10.2215/cjn.03060316
212. Tejani A, Stablein DH (1992) Recurrence of focal segmental glomerulosclerosis posttransplantation: a special report of the North American Pediatric Renal Transplant Cooperative Study. J Am Soc Nephrol 2(12 Suppl):S258-S263

213. Allen PJ, Chadban SJ, Craig JC, Lim WH, Allen RDM, Clayton PA, Teixeira-Pinto A, Wong G (2017) Recurrent glomerulonephritis after kidney transplantation: risk factors and allograft outcomes. Kidney Int 92(2):461-469. https://doi.org/10.1016/j.kint.2017.03. 015

214. Abbott KC, Sawyers ES, Oliver JD 3rd, Ko CW, Kirk AD, Welch PG, Peters TG, Agodoa LY (2001) Graft loss due to recurrent focal segmental glomerulosclerosis in renal transplant recipients in the United States. Am J Kidney Dis 37(2):366-373. https://doi.org/ 10.1053/ajkd.2001.21311

215. Meyer TN, Thaiss F, Stahl RA (2007) Immunoadsorbtion and rituximab therapy in a second living-related kidney transplant patient with recurrent focal segmental glomerulosclerosis. Transpl Int 20(12):1066-1071. https://doi.org/10.1111/j.1432-2277.2007. 00562.x

216. Gohh RY, Yango AF, Morrissey PE, Monaco AP, Gautam A, Sharma M, McCarthy ET, Savin VJ (2005) Preemptive plasmapheresis and recurrence of FSGS in high-risk renal transplant recipients. Am J Transplant Off J Am Soc Transplant Am Soc Transplant Surg 5(12):2907-2912. https://doi.org/10.1111/j. 1600-6143.2005.01112.x

217. Audard V, Kamar N, Sahali D, Cardeau-Desangles I, Homs S, Remy P, Aouizerate J, Matignon M, Rostaing L, Lang P, Grimbert P (2012) Rituximab therapy prevents focal and segmental glomerulosclerosis recurrence after a second renal transplantation. Transpl Int 25(5):e62-e66. https://doi.org/10.1111/j.14322277.2012.01462.x

218. Cleper R, Krause I, Bar Nathan N, Mor M, Dagan A, Weissman I, Frishberg Y, Rachamimov R, Mor E, Davidovits M (2016) Focal segmental glomerulosclerosis in pediatric kidney transplantation: 30 years' experience. Clin Transpl 30(10):1324-1331. https://doi. org/10.1111/ctr.12825

219. Kim EM, Striegel J, Kim Y, Matas AJ, Najarian JS, Mauer SM (1994) Recurrence of steroid-resistant nephrotic syndrome in kidney transplants is associated with increased acute renal failure and acute rejection. Kidney Int 45(5):1440-1445. https://doi.org/10. 1038/ki.1994.188

220. Pelletier JH, Kumar KR, Engen R, Bensimhon A, Varner JD, Rheault MN, Srivastava T, Straatmann C, Silva C, Davis TK, Wenderfer SE, Gibson K, Selewski D, Barcia J, Weng P, Licht C, Jawa N, Kallash M, Foreman JW, Wigfall DR, Chua AN, Chambers E, Hornik CP, Brewer ED, Nagaraj SK, Greenbaum LA, Gbadegesin RA (2018) Recurrence of nephrotic syndrome following kidney transplantation is associated with initial native kidney biopsy findings. 33(10):1773-1780. doi:https://doi.org/10. 1007/s00467-018-3994-3

221. Pardon A, Audard V, Caillard S, Moulin B, Desvaux D, Bentaarit B, Remy P, Sahali D, Roudot-Thoraval F, Lang P, Grimbert P 
(2006) Risk factors and outcome of focal and segmental glomerulosclerosis recurrence in adult renal transplant recipients. Nephrol Dial Transplant 21(4):1053-1059. https://doi.org/10. 1093/ndt/gfk005

222. Myslak M, Amer H, Morales P, Fidler ME, Gloor JM, Larson TS, Stegall MD, Cosio FG (2006) Interpreting post-transplant proteinuria in patients with proteinuria pre-transplant. Am J Transplant Off J Am Soc Transplant Am Soc Transplant Surg 6(7):1660 1665. https://doi.org/10.1111/j.1600-6143.2006.01361.x
223. Araya CE, Dharnidharka VR (2011) The factors that may predict response to rituximab therapy in recurrent focal segmental glomerulosclerosis: a systematic review. J Transplant 2011: 374213. https://doi.org/10.1155/2011/374213

Publisher's note Springer Nature remains neutral with regard to jurisdictional claims in published maps and institutional affiliations.

\section{Affiliations}

Agnes Trautmann ${ }^{1}$ - Marina Vivarelli ${ }^{2}$. Susan Samuel ${ }^{3} \cdot$ Debbie Gipson $^{4} \cdot$ Aditi Sinha $^{5} \cdot$ Franz Schaefer $^{1} \cdot$ Ng Kar Hui $^{6}$. Olivia Boyer ${ }^{7,8}$. Moin A Saleem ${ }^{9} \cdot$ Luciana Feltran $^{10}$. Janina Müller-Deile ${ }^{11}$ • Jan Ulrich Becker ${ }^{12}$. Francisco Cano ${ }^{13}$. Hong $\mathrm{Xu}^{14} \cdot$ Yam Ngo Lim ${ }^{15}$. William Smoyer ${ }^{16}$ • Ifeoma Anochie ${ }^{17} \cdot$ Koichi Nakanishi $^{18}$ • Elisabeth Hodson ${ }^{19}$. Dieter Haffner $20,21,22 \cdot$ on behalf of the International Pediatric Nephrology Association

1 Division of Pediatric Nephrology, Center for Pediatrics and Adolescent Medicine, Heidelberg, Germany

2 Department of Pediatric Subspecialties, Division of Nephrology and Dialysis, Bambino Gesù Pediatric Hospital and Research Center, Rome, Italy

3 Department of Pediatrics, Section of Pediatric Nephrology, Alberta Children's Hospital, University of Calgary, Calgary, Canada

4 Division of Nephrology, University of Michigan, Ann Arbor, MI, USA

5 Department of Pediatrics, Division of Nephrology, All India Institute of Medical Sciences, New Delhi, India

6 Department of Paediatrics, Yong Loo Lin School of Medicine, National University of Singapore, Singapore, Singapore

7 Laboratory of Hereditary Kidney Diseases, Imagine Institute, INSERM U1163, Paris Descartes University, Paris, France

8 Department of Pediatric Nephrology, Reference Center for Idiopathic Nephrotic Syndrome in Children and Adults, Necker Hospital, APHP, 75015 Paris, France

9 Department of Pediatric Nephrology, Bristol Royal Hospital for Children, University of Bristol, Bristol, UK

10 Hospital Samaritano and HRim/UNIFESP, Federal University of São Paulo, São Paulo, Brazil

11 Department of Nephrology, University Hospital Erlangen, Erlangen, Germany
12 Institute of Pathology, University Hospital of Cologne, Cologne, Germany

13 Department of Nephrology, Luis Calvo Mackenna Children's Hospital, University of Chile, Santiago, Chile

14 Department of Nephrology, Children's Hospital of Fudan University, Shanghai, China

15 Department of Pediatrics, Prince Court Medical Centre, Kuala Lumpur, Malaysia

16 The Research Institute at Nationwide Children's Hospital, The Ohio State University, Columbus, OH, USA

17 Department of Paediatrics, University of Port Harcourt Teaching Hospital, Port Harcourt, Rivers State, Nigeria

18 Department of Child Health and Welfare (Pediatrics), Graduate School of Medicine, University of the Ryukyus, Okinawa, Japan

19 Cochrane Kidney and Transplant, Centre for Kidney Research, The Children's Hospital at Westmead and the Sydney School of Public Health, University of Sydney, Sydney, Australia

20 Department of Paediatric Kidney, Liver and Metabolic Diseases, Hannover Medical School Children's Hospital, Hannover, Germany

21 Department of Paediatric Kidney, Liver and Metabolic Diseases, Paediatric Research Center, Hannover Medical School, CarlNeuberg-Str. 1, 30625 Hannover, Germany

22 Center for Rare Diseases, Hannover Medical School Children's Hospital, Hannover, Germany 